\title{
Activation of Hypoxia Signaling in Stromal Progenitors Impairs Kidney Development
}

\author{
Katharina Gerl, ${ }^{*}$ Dominik Steppan, ${ }^{*}$ Michaela Fuchs, ${ }^{*}$ Charlotte Wagner, ${ }^{*}$ Carsten Willam, ${ }^{\dagger}$ Armin Kurtz, ${ }^{*}$ and Birgül Kurt*
}

From the Institute of Physiology, ${ }^{*}$ University of Regensburg, Regensburg; and the Department of Nephrology and Hypertension, ${ }^{\dagger}$ Friedrich-Alexander-University Erlangen-Nürnberg, Erlangen, Germany

Accepted for publication

March 22, 2017.

Address correspondence to Birgül Kurt, Ph.D., Institute of Physiology, University of Regensburg, Universitätsstrasse 31, D-93053 Regensburg, Germany. E-mail: birguel. kurt@ur.de.

\begin{abstract}
Intrauterine hypoxia is a reason for impaired kidney development. The cellular and molecular pathways along which hypoxia exerts effects on nephrogenesis are not well understood. They are likely triggered by hypoxia-inducible transcription factors (HIFs), and their effects appear to be dependent on the cell compartment contributing to kidney formation. In this study, we investigated the effects of HIF activation in the developing renal stroma, which also essentially modulates nephron development from the metanephric mesenchyme. HIF activation was achieved by conditional deletion of the von Hippel-Lindau tumor suppressor (VHL) protein in the forkhead box FOXD1 cell lineage, from which stromal progenitors arise. The resulting kidneys showed maturation defects associated with early postnatal death. In particular, nephron formation, tubular maturation, and the differentiation of smooth muscle, renin, and mesangial cells were impaired. Erythropoietin expression was strongly enhanced. Codeletion of VHL together with HIF2A but not with HIF1A led to apparently normal kidneys, and the animals reached normal age but were anemic because of low erythropoietin levels. Stromal deletion of HIF2A or HIF1A alone did not affect kidney development. These findings emphasize the relevance of sufficient intrauterine oxygenation for normal renal stroma differentiation, suggesting that chronic activity of HIF2 in stromal progenitors impairs kidney development. Finally, these data confirm the concept that normal stroma function is essential for normal tubular differentiation. (Am J Pathol 2017, 187: 1496-1511; http://dx.doi.org/10.1016/j.ajpath.2017.03.014)
\end{abstract}

Although mammalian kidneys normally develop in a hypoxic state, a further decrease of intrauterine oxygen availability, such as in states of placental insufficiency, impairs nephrogenesis and in consequence kidney development, causing life-long health risks. ${ }^{1-5}$ The cellular and molecular mechanisms along which intrauterine hypoxia affects kidney development appear to be complex, and they are yet poorly understood. There appears to exist an optimal low range of tissue oxygen concentrations outside of which kidney development is impaired. Moreover, hypoxia of different cell compartments contributing to kidney formation may exert differential effects on kidney differentiation. The metanephric kidney develops from three major cell pools (namely, ureteric buds, metanephric mesenchyme, and stromal progenitors). ${ }^{6}$ These different cell precursor pools are characterized by their dependency on specific transcription factors. Homeobox protein HOXB7-dependent precursor cells produce ureteric buds and collecting ducts.
Homeobox protein SIX2-dependent precursor cells lead to all epithelial cells of the nephron, including podocytes. Finally, forkhead box FOXD1 dependency defines stromal progenitors developing to interstitial fibroblasts and pericyte-like cells, vascular smooth muscle, mesangial cells, and renin-producing cells. ${ }^{6-8}$

It is commonly assumed that the effects of hypoxia on differentiation are transmitted by hypoxia-inducible transcription factors (HIFs). It has been shown recently that HIF activation in the ureteric buds favors nephrogenesis, whereas HIF activation in the metanephric mesenchyme seems to impair nephrogenesis. ${ }^{9}$ To achieve a better understanding of the mechanisms along which hypoxia affects kidney development, it appears therefore reasonable

Supported by the German Research Foundation grants Ku 859/15-1 and SFB 699

Disclosures: None declared. 
to first analyze hypoxia-induced events in defined cell compartments contributing to the developing kidney. Activation of HIFs in the SIX2 cell lineage producing all epithelial cells of the nephron led to viable mice that developed cysts and fibrosis after several months of life. ${ }^{10}$ Another study in which HIF1 was activated in the HOXB7 cell lineage producing ureteric buds, collecting ducts, and parts of the distal nephron reported the development of viable mice, which developed progressive fibrosis and dilatory tubular changes at an age of 2 months. ${ }^{11}$ In line, stable expression of HIF1 in tubular cells in vivo promotes renal fibrosis. ${ }^{12}$ Although the stromal cell compartment defined by dependency on FOXD1 also essentially modulates nephron development from the metanephric mesenchyme, ${ }^{13,14}$ the effects of hypoxia in stromal precursors on kidney development have so far not been investigated. We therefore analyzed the effects and functional consequences of HIF activation in stromal precursors on kidney development and differentiation. A common way to activate HIFs apart by hypoxia is their stabilization by inhibition/ deletion of individual prolyl 4-hydroxylases (P4Hs) ${ }^{15-21}$ or by deletion of the von Hippel-Lindau tumor suppressor $(V H L)$ gene, which is centrally involved in proteasomal HIF degradation. ${ }^{22,23}$ Because more than one $\mathrm{P} 4 \mathrm{H}$ isoform appears to be relevant for HIF regulation in the renal FOXD1 cell compartment, ${ }^{15}$ we chose deletion of $V H L$ from the FOXD1 compartment as the maneuver for general HIF stabilization. For this purpose, we have generated and characterized a mouse strain carrying Cre recombinase under the control of the FOXD1 promoter and carrying two floxed $V H L$ alleles ( $F O X D 1^{+/ C r e} V H L^{f / f l}$ mice). To confirm HIF dependency of effects observed, we further generated and characterized mice lacking HIFIA or HIF2A in the FOXD1 cell lineage.

We found that deletion of $V H L$ strongly attenuated the differentiation of cells directly deriving from the FOXD1 department. In addition, nephrogenesis was delayed, leading to insufficient kidney function being the likely reason for the early postnatal death. All these changes induced by $V H L$ deletion from the FOXD1-positive compartment were dependent on HIF2 but not on HIF1.

\section{Materials and Methods}

\section{Study Approval}

Institutional review boards for the NIH and the University of Regensburg reviewed and approved the present study, which was performed under the guidelines of NIH's Guide for the Care and Use of Laboratory Animals. ${ }^{24}$

\section{Animals}

Mice with a conditional deletion of $V H L$ in FOXD1expressing cells (FOXD1 ${ }^{+/ C r e} V H L^{f l f l}$ mice) were generated by crossbreeding mice with loxP flanked
$V H L$ alleles $^{25}$ and mice with a FOXD $1^{\text {tml(GFP/cre)Amc }}$ allele, which expresses an enhanced green fluorescent protein (eGFP)-Cre fusion protein from the FOXD1 promoter/ enhancer elements $^{7,26}$ (referred to as FOXD1 ${ }^{+/ C r e}$ mice: 012463; purchased from Jackson Laboratories, Bar Harbor, ME). FOXD1 cell-specific knockout mice for $V H L$ and HIF $2 A\left(F O X D 1^{+/ C r e} V H L^{A / f l} H I F 2 A^{f l / f}\right)$ or only for HIF $2 A$ $\left(F O X D 1^{+/ C r e} H I F 2 A^{f / f}\right)$ were generated by crossing the previously mentioned mouse strains with mice with loxP flanked HIF2A alleles. ${ }^{27}$ FOXD1 cell-specific knockout mice for VHL and HIFlA (FOXD1 ${ }^{+/ C r e} V H L^{f l / f} H I F 1 A^{f / f l}$ ) or only for HIFlA $\left(F O X D 1^{+/ C r e} H I F 1 A^{A I f A}\right)$ were generated by crossing the previously mentioned mouse strains with mice with loxP flanked HIFIA alleles. ${ }^{28} \mathrm{FOXD1}^{+/ \text {Cre }}$ littermates served as controls. For tracing of the FOXD1 cell lineage, FOXD1 $1^{+/ C r e}$ mice were crossed with the membrane-Tomato/membrane-GFP (mT/mG) dual fluorescent reporter mouse strain [007676; purchased from Jackson Laboratories; the $\mathrm{mT} / \mathrm{mG}$ reporter expresses membrane-targeted tdTomato $(\mathrm{mT})$; when bred to Cre recombinase-expressing mice, the resulting offspring have the $m T$ cassette deleted in the Cre-expressing tissue(s), allowing expression of the membrane-targeted $e G F P(m G)$ cassette located just downstream]. ${ }^{29}$ Animals were maintained on standard rodent chow $(0.6 \% \mathrm{NaCl}$; Ssniff, Soest, Germany) with free access to tap water. Animals used in this study were in the embryonic state of embryonic day 16/18, newborn, 7 days old, or 7 weeks old. All animal experiments were performed according to the Guidelines for the Care and Use of Laboratory Animals, published by the NIH, and approved by the local ethics committee.

\section{Determination of Hematocrit, Plasma EP0, and Plasma REN Levels}

Blood samples were taken into capillary tubes containing $1 \mu \mathrm{L} 125 \mathrm{mmol} / \mathrm{L}$ EDTA to prevent clotting. Hematocrit values were determined after centrifugation $(12,000 \times g$ for 4 minutes at room temperature $)$. The erythropoietin (EPO) protein concentration was determined in plasma samples using the Quantikine Mouse EPO ELISA kit (R\&D Systems, Minneapolis, MN), according to the manufacturer's protocol. Renin (REN) concentration in plasma samples was measured on the basis of the generation of angiotensin-I after the addition of plasma from bilaterally nephrectomized male rats as excess renin substrate. The generated angiotensin-I (ng angiotensin-I/hour per $\mathrm{mL}$ ) was determined by radioimmunoassay (Byk \& DiaSorin Diagnostics, Dietzenbach, Germany). ${ }^{30}$

\section{Determination of mRNA Expression by Real-Time PCR}

Total RNA was isolated from kidneys, as described by Chomczynski and Sacchi, ${ }^{31}$ and quantified by a 
photometer. One microgram of the resulting RNA was used for reverse transcription. The cDNA was synthesized by Moloney murine leukemia virus RT (Life Technologies, Carlsbad, CA). For quantification of mRNA expression, real-time PCR was performed using a Light Cycler Instrument and the LightCycler 480 SYBR Green I Master Kit (Roche Diagnostics, Indianapolis, IN) and ribosomal protein L32 as a control. Table 1 lists the primer sequences.

\section{Microarray Analysis}

RNA of kidneys from 18-day-old embryos ( $n=4$ for each genotype) was analyzed. RNA quality control, sample preparation, and processing with Affymetrix Mouse Gene 2.0 ST arrays (Affymetrix, Santa Clara, CA) were performed at an Affymetrix Service Provider and Core Facility, KFB-Center of Excellence for Fluorescent Bioanalytics (KFB, Regensburg, Germany). Gene expression data were

Table 1 Primer Sequences Used for Real-Time PCR

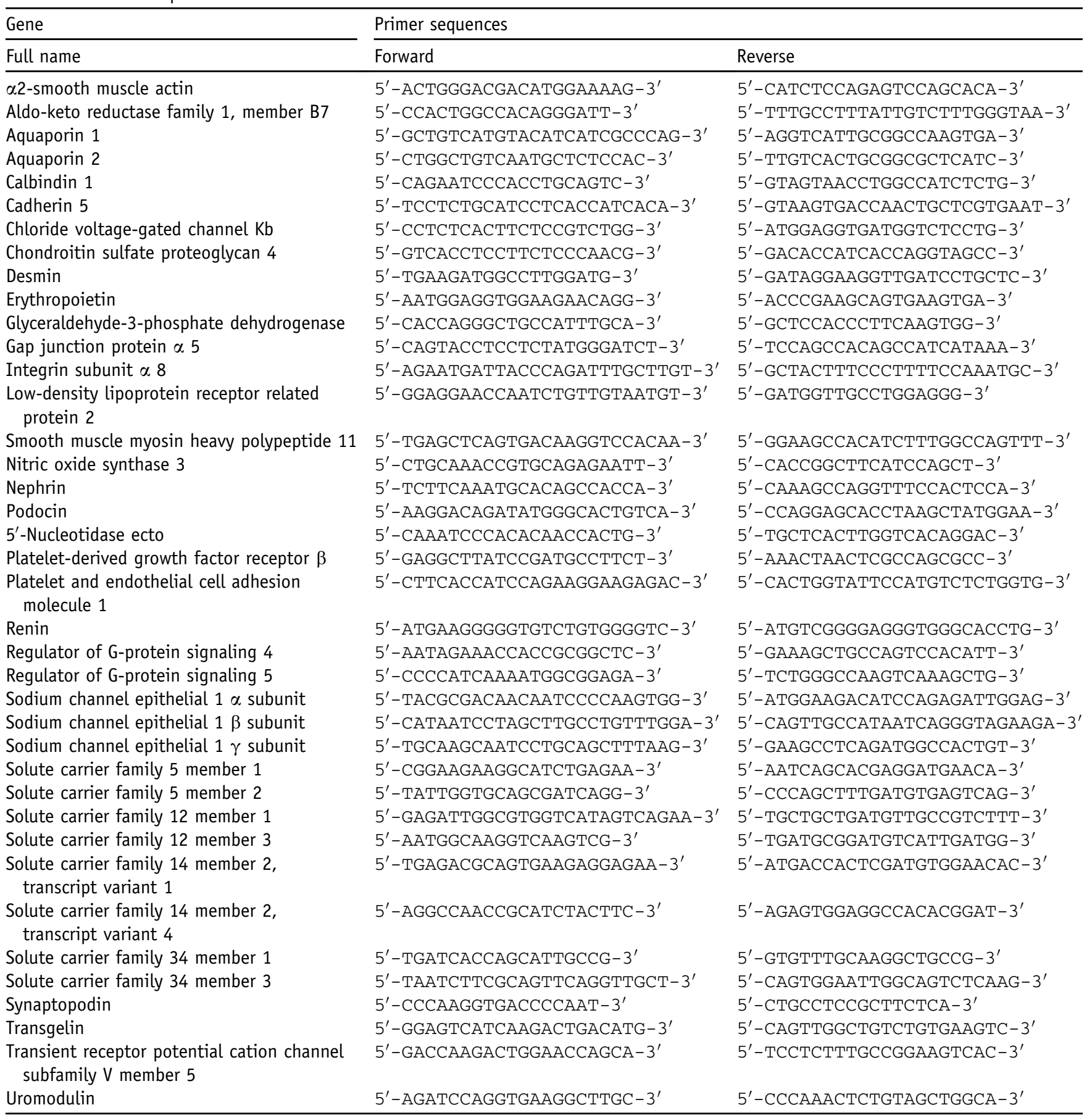


Table 2 Antibodies Used for Immunohistochemistry

\begin{tabular}{|c|c|c|}
\hline \multicolumn{3}{|l|}{ Antigene } \\
\hline Full name & Manufacturer & Catalog number \\
\hline a2-Smooth muscle actin & Abcam, Inc. (Cambridge, UK) & ab7817 \\
\hline Calbindin 1 & Swant (Marly, Switzerland) & Code no: 300 \\
\hline Platelet and endothelial cell adhesion molecule 1 & R\&D Systems (Minneapolis, MN) & AF3628 \\
\hline Gap junction protein $\alpha 5$ & Biotrend (Köln, Germany) & Cx40-A \\
\hline Low-density lipoprotein receptor related protein 2 & Santa Cruz & sc-16478 \\
\hline Nephrin & Acris (Rockville, MD) & $1243-1256$ \\
\hline Solute carrier family 12 member 1 & Millipore (Billerica, MA) & AB3562P \\
\hline Platelet-derived growth factor receptor $\beta$ & Abcam, Inc. & ab32570 \\
\hline Renin & Davids Biotechnology (Regensburg, Germany) & \\
\hline
\end{tabular}

generated at the KFB with Affymetrix GeneChip Command Console version 4.1.3 and Affymetrix Expression Console version 1.4 software packages.

\section{Immunohistochemistry}

Kidneys were perfusion fixed with $3 \%$ paraformaldehyde/ phosphate-buffered saline, dehydrated, and embedded in paraffin. For fluorescence images, sagittal sections (5 $\mu \mathrm{m}$ thick) were blocked with $10 \%$ horse serum/1\% bovine serum albumin in phosphate-buffered saline before the primary antibodies were applied. After three washes, sections were stained with Cy2, Cy5, tetramethylrhodamine B isothiocyanate, and Alexa Fluor 350 secondary antibodies. Staining of HIF1A and HIF2A was performed as described by Schley et al. ${ }^{32}$ Paraffin-embedded kidney sections ( $4 \mu \mathrm{m}$ thick) were incubated with the following primary antibodies: mouse anti-human HIF1A ( $\alpha 67$; Novus Biologicals, Littleton, CO) and rabbit anti-mouse HIF2A (PM9). ${ }^{33}$ Primary antibodies were detected by using biotinylated secondary anti-mouse or anti-rabbit antibodies and a catalyzed signal amplification system (Dako, Hamburg, Germany) based on the streptavidin-biotin-peroxidase reaction, according to the instructions provided by the manufacturer. Slices were mounted with DakoCytomation Glycergel mounting medium (DakoCytomation, Glostrup, Denmark) and were viewed with an Axiovert microscope (Axiovert, Oberkochen, Germany). Table 2 lists the primary antibodies used for immunohistochemistry.

\section{Immunoblot Analysis for the Hypoxia-Inducible} Factors HIF1A, HIF2A, and Actin $\beta$

Kidneys from 7-day-old $F O X D 1^{+/ C r e}$ and $F O X D 1^{+/ C r e}$ $V H L^{f / f l}$ mice were homogenized in lysis buffer. After a centrifugation step for 5 minutes at $10,600 \times g\left(4^{\circ} \mathrm{C}\right)$, protein concentrations were determined from the supernatant. Aliquots of $50 \mu \mathrm{g}$ of protein for the HIF1A and HIF2A and $5 \mu \mathrm{g}$ of protein for the actin $\beta$ immunoblot were electrophoretically separated on $10 \%$ polyacrylamide gels and transferred to nitrocellulose membranes, which were blocked overnight in 5\% nonfat dry milk diluted in Tris-buffered saline with $0.1 \%$ Tween-20. The membranes were then incubated for 1 hour at room temperature with antibodies against HIF1A (10006421; 1:2000; Cayman,
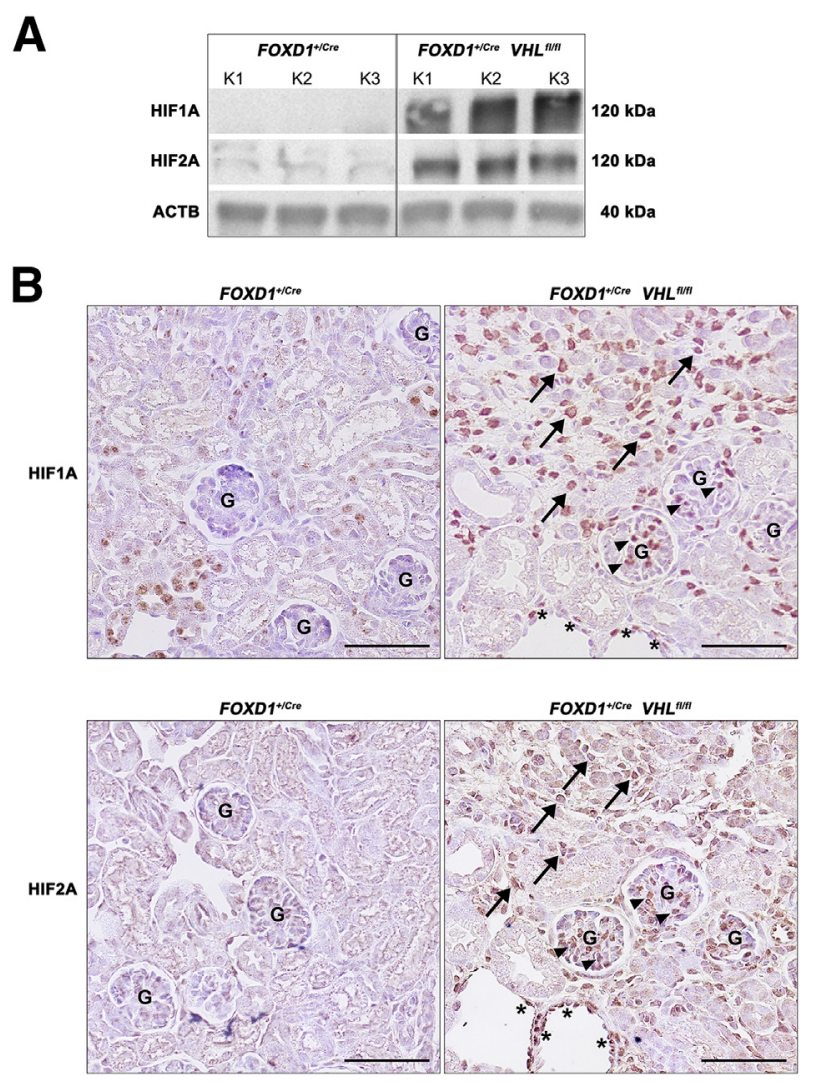

Figure 1 Stabilization of HIF1A and HIF2A in the FOXD1 cell lineage in FOXD1 ${ }^{+/ C r e} \mathrm{VHL}^{f l f l}$ kidneys. A: Protein abundance of HIF1A and HIF2A was determined in three kidneys (K1, K2, and K3) of 7-day-old FOXD1 $1^{+/ C r e}$ (control litters) and FOXD1 ${ }^{+/ C r e} V H L^{f Y f l}$ mice, respectively. Analysis of actin $\beta$ (ACTB) served as a loading control. B: Immunohistochemical staining of FOXD1 $1^{+/ C r e} \mathrm{VHL}^{f / f l}$ kidneys shows an immense enrichment of HIF1A and HIF2A in the interstitium (arrows), intraglomerular mesangial cells (arrowheads), and perivascular cells (asterisks). Scale bars $=100 \mu \mathrm{m}$ (B). G, glomerulus. 
Table 3 Parameters of 7-Day-Old FOXD1 $1^{+/ C r e}$ and FOXD1 ${ }^{+/ C r e} V H L^{f / f L}$ Mice

\begin{tabular}{lcc}
\hline Parameter & FOXD1 & \\
\hline Body weight, g & $4.94 \pm 0.18$ & FOXD1 \\
Hematocrit, \% & $3.30 \pm 0.15^{* * *}$ \\
Plasma EP0, pg/mL & $777.7 \pm 0.3$ & $43.3 \pm 0.6^{* * *}$ \\
Plasma REN, ng & $46.1 \pm 5.9$ & $22,770.0 \pm 3278.1^{* * *}$ \\
$\quad$ Ang-I/hour $\times \mathrm{mL}$ & & $8.3 \pm 1.3^{* * *}$ \\
Relative organ weights, \% & \\
$\quad$ Brain & $5.32 \pm 0.35$ & $6.51 \pm 0.41$ \\
Heart & $0.57 \pm 0.02$ & $0.62 \pm 0.03$ \\
Kidney (left) & $0.55 \pm 0.02$ & $0.40 \pm 0.02^{* * *}$ \\
Liver & $2.91 \pm 0.09$ & $2.83 \pm 0.19$ \\
Lung & $2.21 \pm 0.17$ & $2.48 \pm 0.26$ \\
Spleen & $0.58 \pm 0.04$ & $0.93 \pm 0.05^{* * *}$ \\
\hline
\end{tabular}

Body weights, relative organ weights (related to body weight), hematocrit values, and plasma concentrations of EPO and REN of FOXD $1^{+/ C r e} V_{H L}{ }^{f l f l}$ mice and their controls $\left(F o x D 1^{+/ C r e}\right)$ at day 7 after birth. Data are expressed as means \pm SEM. $n=22$ control mice; $n=16$ FOXD1 ${ }^{+/ C r e} V H L^{f l f l}$ mice.

EP0, erythropoietin; REN, renin.

$\star * \star P<0.001$ versus FOXD1 $1^{+/ C r e}$.

Hamburg, Germany), HIF2A (NB100-122; 1:500; Novus Biologicals, Wiesbaden, Germany), or actin $\beta$ (A5316; 1:5000; Sigma-Aldrich, St. Louis, MO). After washing, the membranes were incubated for 2 hours with corresponding secondary antibodies (1:2000; Santa Cruz Biotechnology, Dallas, TX) and were subjected to a chemiluminescence detection system.

\section{Three-Dimensional Reconstruction}

Antibody-stained serial sections (100 sections) were digitized using an AxioCam MRm camera (Zeiss, Oberkochen, Germany) mounted on an Axiovert 200M microscope (Zeiss) with fluorescence filters for REN and $\alpha 2$-smooth muscle actin (ACTA2) (tetrarhodamine isothiocyanate, filter set 43; Cy2, filter set $38 \mathrm{HE}$; Zeiss). After acquisition, a stack of equal-size images was built using the graphic tool ImageJ version 1.48 (NIH, Bethesda, MD; http://imagej.nih. gov/ $i j)$. The equalized data were then imported into the Amira 5.3 visualization software (Mercury Computer Systems, Chelmsford, MA) on a Dell Precision 690 computer system (Dell Technologies, Round Rock, TX) and split into the REN and ACTA2 channels. After this step, the REN and ACTA2 channels were aligned. In the segmentation step, the ACTA2 and REN data sets served as a scaffold and were spanned manually or automatically using gray scale values. Matrices, volume surfaces, and statistics were generated from these segments. ${ }^{34}$

\section{Statistical Analysis}

All data are expressed as means \pm SEM. Statistical significance was determined by $t$-test for intraindividual comparison, and by analysis of variance and Bonferroni's adjustment for multiple comparisons between experimental groups. $P<0.05$ was considered statistically significant.
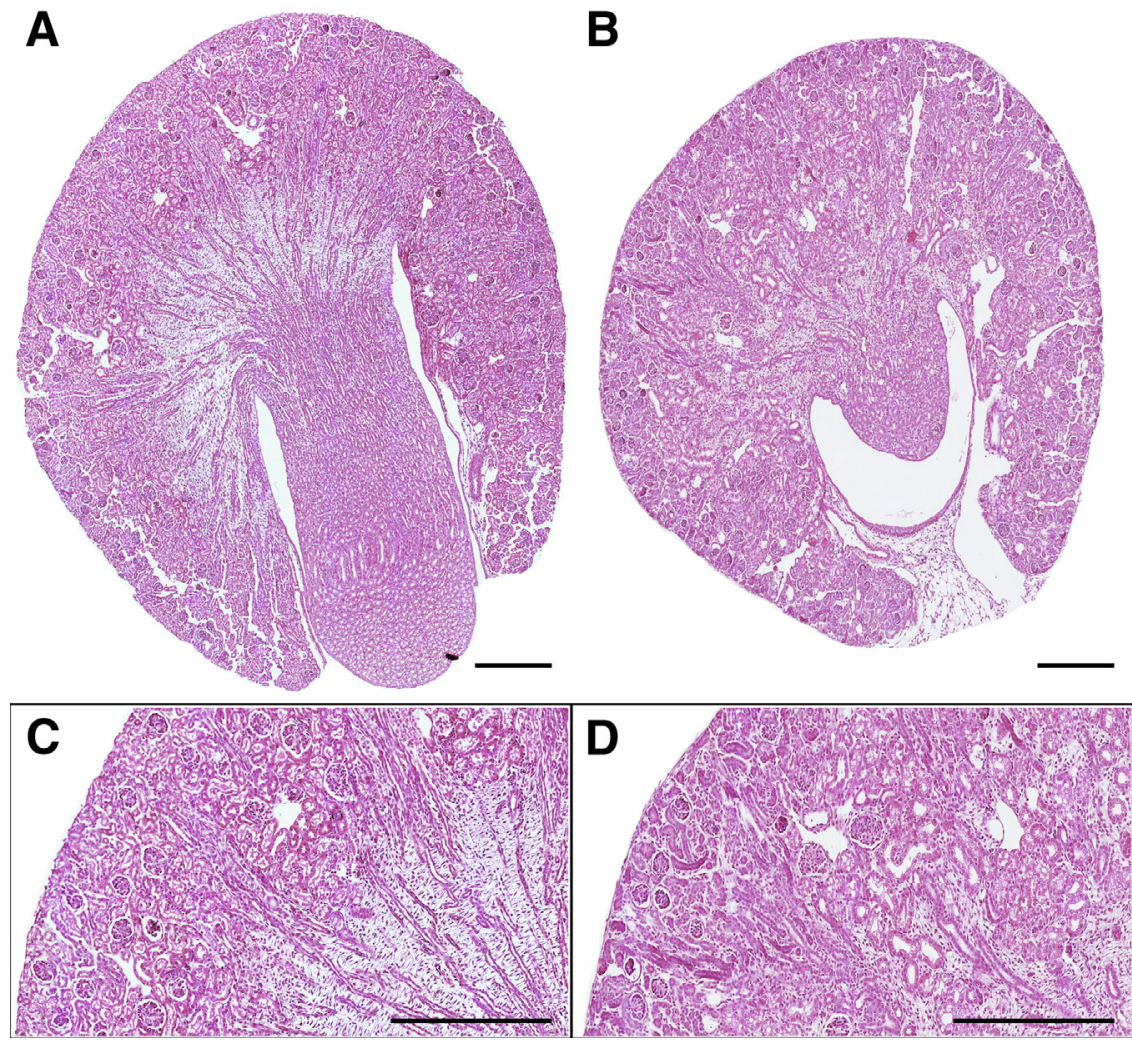

Figure 2 Kidneys of FOXD1 $1^{+/ C r e} \quad \mathrm{VHL}^{f / f l}$ knockout mice are smaller and have a less organized structure. Low (A and $\mathbf{B})$ and high ( $\mathbf{C}$ and $\mathbf{D})$ power magnifications of hematoxylin and eosin-stained kidney sections from a FOXD1 ${ }^{+/ C r e}$ control mouse (A and C) and FOXD1 $1^{+/ C r e} \mathrm{VHL}^{f l f l}$ knockout mouse (B and D) at day 7 after birth. Scale bars $=200 \mu \mathrm{m}$ (A-D). 

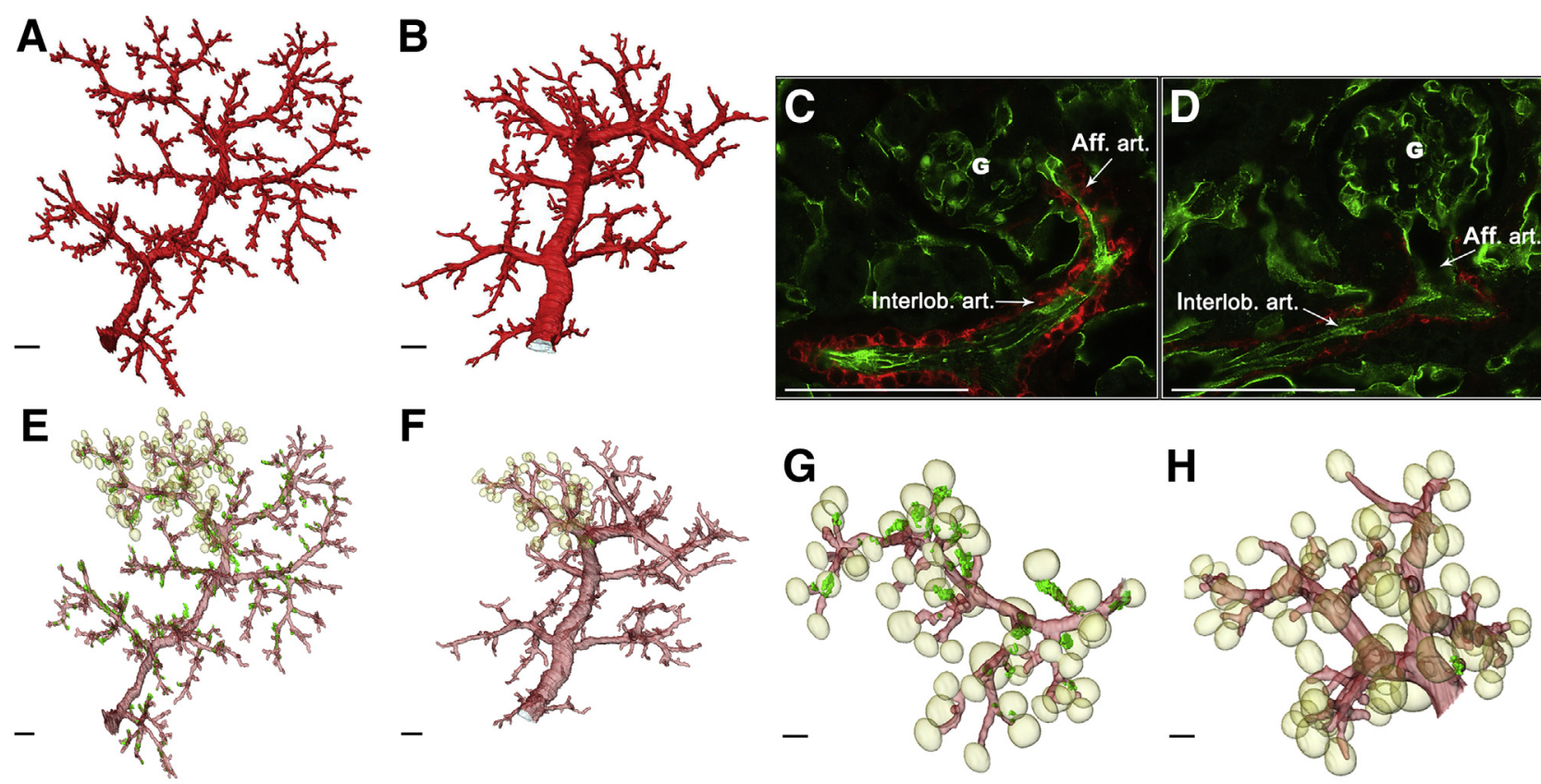

Figure 3 The VHL deficiency in the FOXD1 cell lineage impairs the differentiation of vascular smooth muscle and renin expressing cells. A and B: Threedimensional reconstruction of renal preglomerular vessel trees from 7-day-old FOXD1 ${ }^{+/ C r e}$ control (A) and FOXD1 $1^{+/ C r e}$ VHL $L^{f l f l}$ knockout (B) mice. C and D: Coimmunostaining of ACTA2 (red) and platelet and endothelial cell adhesion molecule 1 (green) in kidneys of a FOXD1 $1^{+/ C r e}$ (C) and a FOXD1 ${ }^{+/ C r e}$ VHL $L^{f l f l}$ mouse (D) at day 7 after birth. E and F: Three-dimensional reconstruction of preglomerular vessel trees (red), including renin-expressing cells (green), from a 7-day-old control $(\mathbf{E})$ and $F O X D 1^{+/ C r e} V H L^{f l f l}(\mathbf{F})$ kidney. $\mathbf{G}$ and $\mathbf{H}$ : A higher magnification of $\mathbf{E}$ and $\mathbf{F}$, respectively, with reconstructed glomeruli. Scale bars $=100 \mu \mathrm{m}(\mathbf{A}-\mathbf{H})$. Aff. art., afferent arteriole; $\mathbf{G}$, glomerulus; Interlob. art., interlobular artery.

\section{Results}

FOXD1 lineage tracing (Supplemental Figure S1), using $F O X D 1^{+/ C r e} m T / m G$ reporter mice, was performed to confirm the sites of renal Cre expression. Interstitial cells, (peri)vascular cells, mesangial cells, juxtaglomerular cells of afferent arterioles, and few tubular cells were labeled by the eGFP reporter, what is in accordance with the present concept of renal cells deriving from FOXD1 stromal cells. $^{26,35}$

\section{FOXD1 ${ }^{+/ C r e} V_{H L}^{f l f l}$ Mice Die Perinatally Most Likely Because of Problems in Kidney Development}

Induction of hypoxia signaling was achieved by conditional deletion of $V H L$ in stromal precursors of the kidney defined by the FOXD1 cell lineage. As a consequence, protein abundance of HIF1A and HIF2A in the developing kidneys (Figure 1A) was increased with an intense enrichment in the interstitium and in mesangial cells (Figure 1B). The $\mathrm{FOXD1}^{+/ C r e}$ control kidneys show a weak expression of HIF1A in tubular cells, but are blank for an HIF2A-positive signal. Mice were born with normal mendelian distribution. Body weight at birth was normal, but postnatal body weight gain and life span were reduced in all $F O X D 1^{+/ C r e} V H L^{f / f t}$ mice, with death occurring at approximately day 10 to 12 after birth. Already at birth, kidney weight was reduced to $83 \%$ of control values (left kidney: $7.6 \pm 0.3 \mathrm{mg}$ for control, $n=5 ;$ and $6.3 \pm 0.3 \mathrm{mg}$ for $\left.F O X D 1^{+/ C r e} V H L^{f l / f}, n=4\right)$. Analysis of animals at day 7 after birth revealed a $33 \%$ reduction of body weight and a $52 \%$ reduction of kidney weight compared to controls (Table 3). Kidneys of 7-day-old $\mathrm{FOXDI}^{+/ C r e} \mathrm{VHL}^{\mathrm{Alfl}}$ mice showed a zonal distribution with medulla, cortex, and subcortical nephrogenic zone similar to control $\left(F O X D 1^{+/ C r e}\right)$ kidneys (Figure 2, A and B). At first inspection, tubules, which already developed cortex zone, appeared reduced in number and less organized (Figure 2, C and D).

\section{Deletion of VHL Leads to a Reduced Number of Nephrons}

Seven days after birth, the absolute number of glomeruli in FOXD $1^{+/ C r e} V_{H L}^{f / f l}$ kidneys was reduced by approximately $50 \%$ relative to controls [166 \pm 4 and $87 \pm 3$ glomeruli per cross kidney section for controls $(n=4)$ and $F O X D 1^{+/ C r e}$ $V H L^{f l / f}(n=4)$ mice, respectively; $\left.P<0.05\right]$, which was in proportion to the lower kidney weight (Table 3). Average glomerular volumes were not different between the two genotypes $\left(76 \pm 6 \mathrm{pL}\right.$ for $F O X D 1^{+/ C r e}$ versus $83 \pm 8 \mathrm{pL}$ for FOXDI $\left.{ }^{+/ C r e} V H L^{f / A}\right)$. The reduced number of glomeruli became also apparent from three-dimensional reconstructions of the preglomerular vessel tree, which showed less afferent arterioles (Figure 3). These findings suggest that nephron formation was reduced in $F O X D 1^{+/ C r e}$ $V H L^{f l f l}$ mice. 

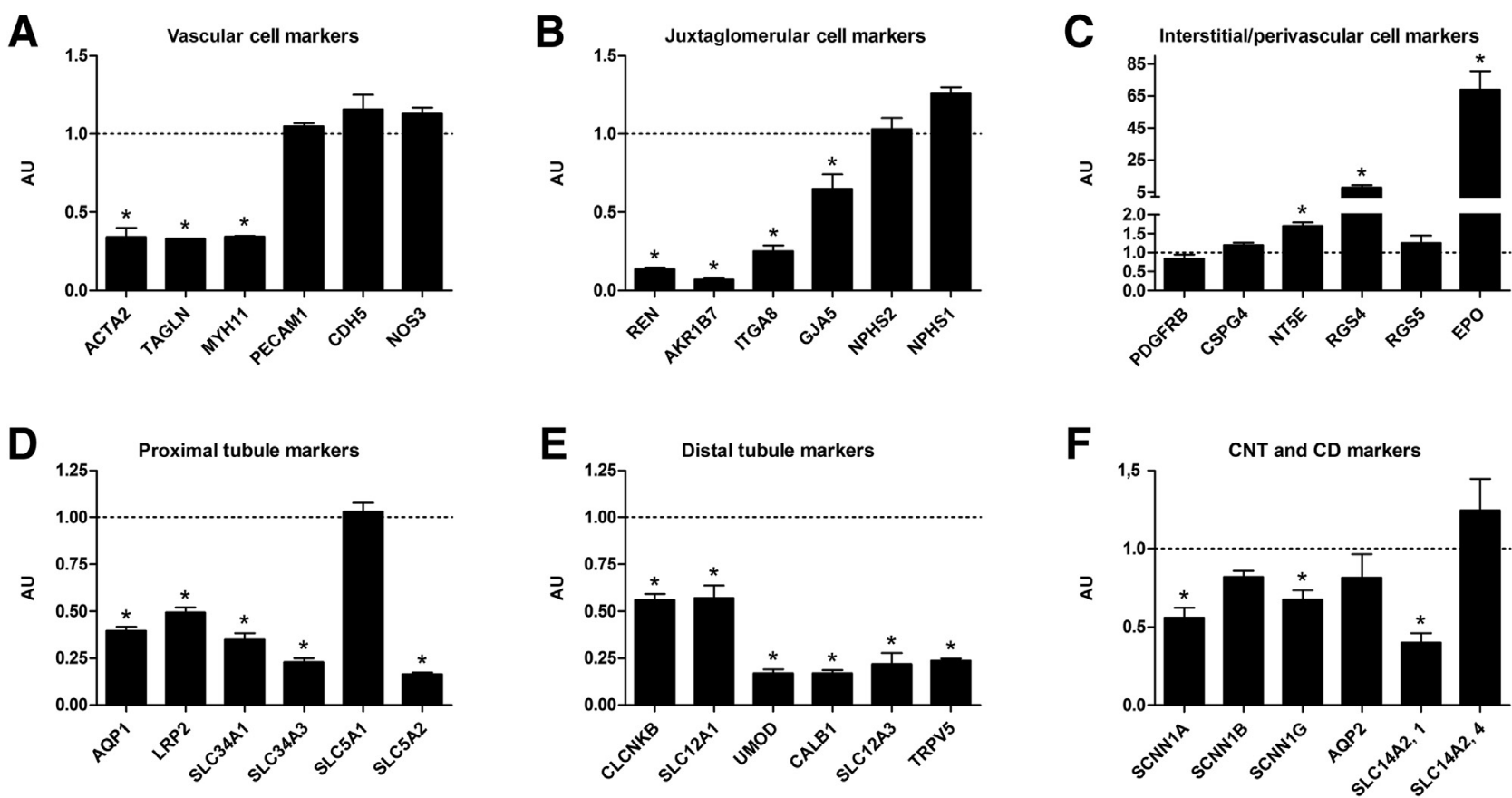

Figure 4 Gene expression profile of $F O X D 1^{+/ C r e} V H L^{f l f l}$ kidneys with cell-specific markers. mRNA abundance of the smooth muscle cell markers ACTA2, transgelin (TAGLN), smooth muscle myosin heavy polypeptide 11 (MYH11), and the endothelial markers platelet and endothelial cell adhesion molecule 1 (PECAM1), cadherin 5 (CDH5), and nitric oxide synthase 3 (NOS3; A); REN, aldo-keto reductase family 1, member B7 (AKR1B7), integrin subunit $\alpha 8$ (ITGA8), and gap junction protein $\alpha 5$ (GJA5) as markers for juxtaglomerular and mesangial cells as well as podocin (NPHS2) and nephrin (NPHS1) as markers for podocytes (B); platelet-derived growth factor receptor $\beta$ (PDGFRB), chondroitin sulfate proteoglycan 4 (CSPG4), NT5E, RGS, and EP0 as markers for interstitial pericyte-like cells (C); AQP1, LRP2, SLC34A1, SLC34A3, SLC5A1, and SLC5A2 transporters (D); CICNKB, solute carrier family 12 member 1 (SLC12A1), uromodulin (UMOD), SLC12A3, calbindin 1 (CALB1), and transient receptor potential cation channel subfamily V member 5 (TRPV5; E); and sodium channel epithelial 1 (SCNN1) subunits, AQP2, and urea transporters solute carrier family 14 member 2 (SLC14A2) transcript variants 1 and 4 (F) in control and in FOXD1 ${ }^{+/ C r e} V H L^{f / f l}$ kidneys. mRNA expression levels of the control mice are set to 1 (dashed lines) and serve as a reference. Ribosomal protein L32 was used as a control. Data are expressed as means \pm SEM. $n=5$ kidneys per group $(\mathbf{A}-\mathbf{F})$. ${ }^{*} P<0.05$ versus control. AU, arbitrary unit; SLC5A1, solute carrier family 5 member $1 ;$ SLC5A2, solute carrier family 5 member 2; SLC34A1, solute carrier family 34 member 1; SLC34A3, solute carrier family 34 member 3.

\section{Deletion of VHL Causes Differentiation Defects of} Renin, Mesangial, and Vascular Smooth Muscle Cells

Apart from the rarefication of preglomerular arteries, the vasculature showed no general major malformations of the architecture of the preglomerular vascular tree in $\mathrm{FOXDI}^{+/ C r e} \mathrm{VHL}^{\mathrm{flf} / \mathrm{A}}$ kidneys (Figure 3B) when compared to controls (Figure 3A). Of note, the diameter of the preglomerular vessels appeared larger (Figure 3B). Conversely, the smooth muscle cells of the arterioles in $\mathrm{FOXDI}^{+/ C r e}$ $V H L^{f / f t}$ kidneys were thinner (Figure 3D). Wall thickness of afferent arterioles was significantly reduced from $3.14 \pm 0.19 \mu \mathrm{m}$ in control mice to $1.97 \pm 0.10 \mu \mathrm{m}$ in FOXD1 $1^{+/ C r e} V H L^{f l f l}$ kidneys. The immunostaining of FOXD1 $1^{+/ C r e} V H L^{f l f l}$ vessels for ACTA2 appeared more faint, whereas the immunoreactivity for the endothelial marker platelet and endothelial cell adhesion molecule 1 (alias CD31) appeared with similar intensity (Figure 3, C and D). In accordance, the mRNA abundance of marker proteins for smooth muscle cells, such as ACTA2, transgelin, or smooth muscle myosin heavy polypeptide 11, was reduced to one third of control kidneys (Figure 4A). In contrast, the expression of endothelial marker proteins and their mRNAs, such as platelet and endothelial cell adhesion molecule 1 , cadherin 5 , or nitric oxide synthase 3 , was not different between $F O X D 1^{+/ C r e} V H L^{f l / f}$ and control kidneys (Figure 3, C and D, and Figure 4A).

A clear difference between the two genotypes was the almost complete absence of juxtaglomerular REN immunoreactive cells in $F O X D 1^{+/ C r e} V H L^{f l / f}$ kidneys (Figure 3, E-H, and Figure 5, A and B). This histological observation was confirmed by low mRNA expression levels of markers for renin cells, such as REN or aldo-keto reductase family 1 , member B7, and gap junction protein $\alpha 5$ (alias CX40) (Figure 4B). In accordance, plasma REN concentrations were markedly reduced in FOXD1 $1^{+/ C r e} V H L^{A / f l}$ mice (Table 3).

Mesangial cells, as indicated by the expression of the platelet-derived growth factor receptor $\beta$, appeared in normal numbers within glomeruli (Figure 5, C and D). The expression of more specific mesangial cell markers, such as integrin subunit $\alpha 8$ (Figure 4B and Figure 5, E and F) and gap junction protein $\alpha 5$ (Figure 4B and Figure 5, G and H), was clearly reduced.

Morphometric analysis revealed an almost 50\% reduction of intraglomerular areas immunoreactive for integrin subunit $\alpha 8$ in $F O X D 1^{+/ C r e} V H L^{f / f l}$ kidneys relative to control kidneys (2155 \pm 277 and $3920 \pm 277$ pixels per glomerulus for $F_{O X D 1^{+/ C r e}} V H L^{f l / f}$ and for FOXD1 $1^{+/ C r e}$ kidneys, 


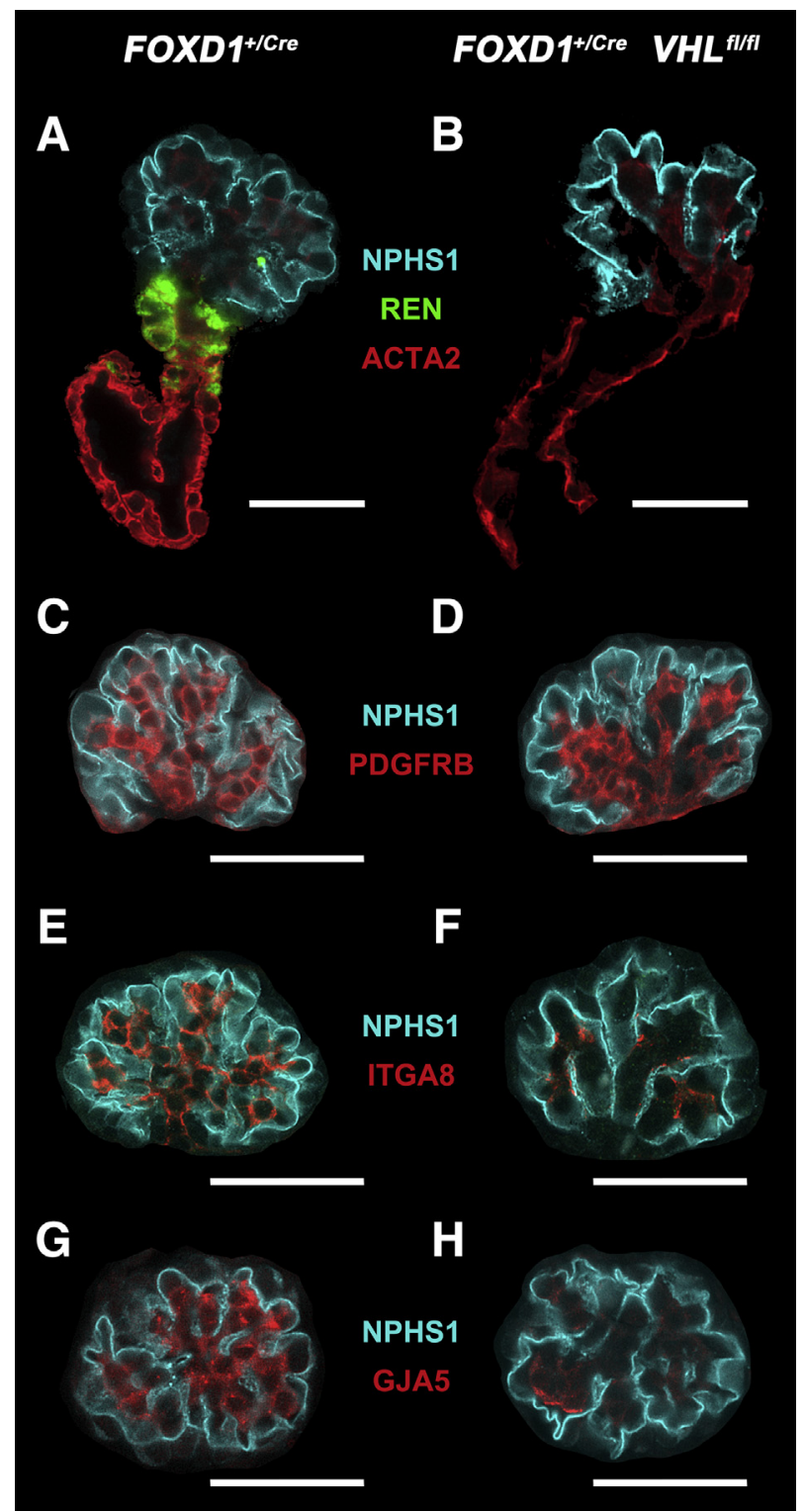

Figure 5 The VHL deficiency in the FOXD1 cell lineage impairs the differentiation but not the development of mesangial cells. A and B: Coimmunostaining of nephrin (NPHS1; cyan), ACTA2 (red), and REN (green) demonstrates the lack of REN expression as well as the widened lumen of the afferent arteriole in the knockout (KO) genotype. C and D: Coimmunostaining of NPHS1 and the mesangial cell marker platelet-derived growth factor receptor $\beta$ (PDGFRB; red) shows no difference in the expression pattern or in the intensity of PDGFRB. E-H: However, the expression of the mesangial cell-specific markers integrin subunit $\alpha 8$ (ITGA8; $\mathbf{E}$ and $\mathbf{F}$ ) and gap junction protein $\alpha 5$ (GJA5; $\mathbf{G}$ and $\mathbf{H}$ ) is markedly reduced in the $\mathrm{K} 0$ genotype. Scale bars $=50 \mu \mathrm{m}(\mathbf{A}-\mathbf{H})$.

respectively; $P<0.05$ ). Intraglomerular areas immunoreactive for gap junction protein $\alpha 5$ were also reduced by almost $70 \%$ in $F O X D 1^{+/ C r e} V H L^{f l / f t}$ kidneys $(289 \pm 50$ and $996 \pm 68$ pixels per glomerulus for $F O X D 1^{+/ C r e} V H L^{f / f t}$ and for $F O X D 1^{+/ C r e}$ kidneys, respectively; $P<0.05$ ).

In contrast, the expression of podocyte markers, such as podocin (Figure 4B) and nephrin (Figure 4B and Figure 5 ), was not different between $F O X D 1^{+/ C r e} V H L^{f / f t}$ and control kidneys.
Table 4 Gene Expression Profile of Profibrotic Markers

\begin{tabular}{lll}
\hline Profibrotic markers & FOXD1 & FOXD1 \\
\hline COL1A1 & $1.00 \pm 0.05$ & $0.67 \pm 0.01^{*}$ \\
COL1A2 & $1.00 \pm 0.03$ & $0.75 \pm 0.04$ \\
COL3A1 & $1.00 \pm 0.03$ & $0.61 \pm 0.01^{*}$ \\
COL4A3 & $1.00 \pm 0.05$ & $1.12 \pm 0.02$ \\
COL18A1 & $1.00 \pm 0.06$ & $1.29 \pm 0.08$ \\
FN1 & $1.00 \pm 0.04$ & $0.55 \pm 0.02^{*}$ \\
\hline
\end{tabular}

mRNA abundance of COL1A1, COL1A2, COL3A1, COL4A3, COL18A1, and FN1 in kidneys of 7-day-old FOXD1 $1^{+/ C r e}$ and FOXD1 $1^{+/ C r e} \mathrm{VHL}^{f l f l}$ mice. mRNA expression levels of the control mice are set to 1 and serve as a reference. Ribosomal protein L32 was used as a control. Data are expressed as means \pm SEM. $n=6$ mice per group.

COL1A1, collagen type I $\alpha 1$ chain; COL1A2, collagen type I $\alpha 2$ chain; COL3A1, collagen type III $\alpha 1$ chain; COL4A3, collagen type IV $\alpha 3$ chain; COL18A1, collagen type XVIII $\alpha 1$ chain; FN1, fibronectin 1 .

${ }^{*} P<0.05$ versus $F O X D 1^{+/ C r e}$.

The development of the renal interstitial stroma, including perivascular cells, was assayed by the expression of markers for interstitial pericyte-like cells, such as plateletderived growth factor receptor $\beta, 5^{\prime}$-nucleotidase ecto (NT5E; alias CD73), chondroitin sulfate proteoglycan 4 (alias NG2), and regulators of G-protein signaling (RGSs). Among these markers, we noted a moderate up-regulation of NT5E and strong up-regulation of RGS4 and EPO (Figure $4 \mathrm{C}$ ). The strong increase of renal EPO gene expression was also reflected by high plasma EPO concentrations and by the polycythemia developing in

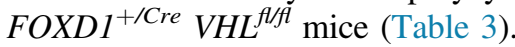

To determine if $V H L$ deletion might have shifted the stromal precursor cells to more profibrotic cells, we analyzed the expression of profibrotic markers. Collagen types COL1A1 and COL3A1 as well as fibronectin $1 \mathrm{mRNA}$ abundance in $\mathrm{FOXDI}^{+/ C r e} \mathrm{VHL}^{\mathrm{Alfl}}$ kidneys decreased rather than increased relative to control kidneys (Table 4).

\section{Deletion of VHL in Stromal Precursor Cells Causes Maturation Defects of Tubular Cells}

In addition to the reduction in nephron numbers, tubular maturation was clearly attenuated in FOXD1 $1^{+/ C r e} V H L^{f l / f}$ kidneys. Gross microscopies of kidney sections already indicated marked reduction in the immunoreactivities for lowdensity lipoprotein receptor-related protein 2 (LRP2; alias megalin), solute carrier family 12 member 1 (alias NKCC2), aquaporin 2 (AQP2), and calbindin 1, marking proximal tubules, thick ascending limbs of the loop of Henle, collecting ducts, and distal tubules, respectively (Supplemental Figure S2). In accordance, expression of marker genes for proximal tubules, such as $L R P 2$, glucose (alias sGLT), and phosphate (alias $\mathrm{NaP}_{\mathrm{i}}$ ) transporters, and water channel $A Q P 1$ was reduced to different extents in $F O X D 1^{+/ C r e} V_{H L}^{A l f l}$ kidneys (Figure 4D). mRNA expression levels of markers for thick ascending limbs of the loop of Henle, such as solute carrier family 12 member 1 , uromodulin, or the chloride voltage-gated channel CLCNKB, were also clearly lowered 


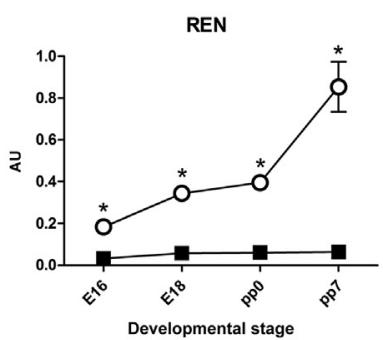

UMOD

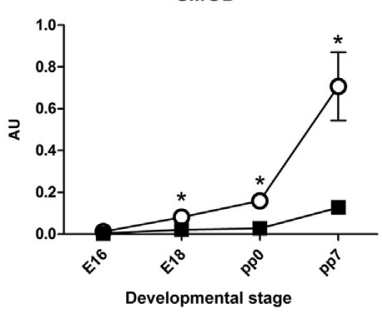

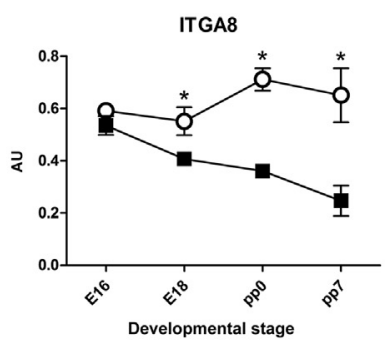

SCNN1A

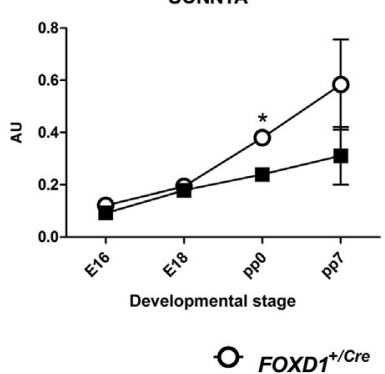

MYH11

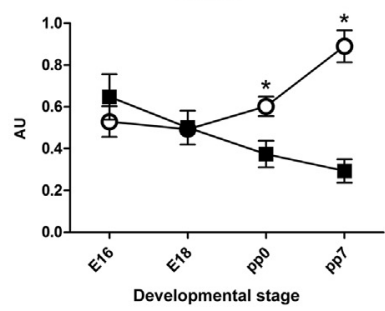

EPO

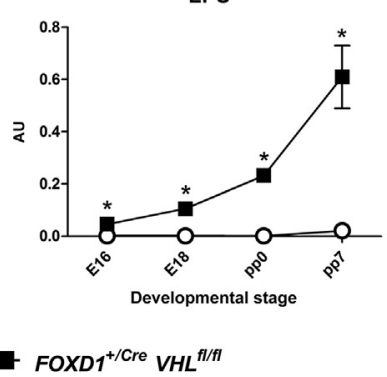

LRP2

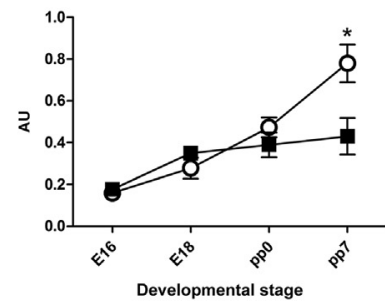

GAPDH

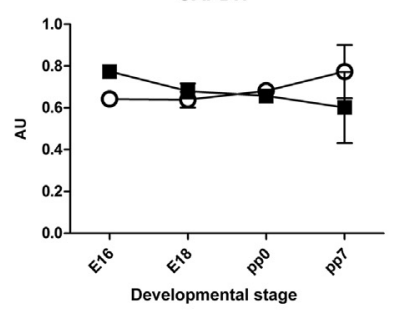

Figure 6 Temporal patterns of gene expression profiles of FOXD1 ${ }^{+/ C r e} V H L^{f l f l}$ kidneys during kidney development. mRNA abundance of REN, integrin subunit $\alpha 8$ (ITGA8), smooth muscle myosin heavy polypeptide 11 (MYH11), and EP0 as markers of stromal-derived cells and LRP2, uromodulin (UMOD), and sodium channel epithelial $1 \alpha$ subunit (SCNN1A) as markers of tubular cells at embryonic days (E) 16 and E18, at the days of birth (pp0), and 7 days after birth (pp7). mRNA abundance for glyceraldehyde-3-phosphate dehydrogenase is shown for comparison as it does not change during kidney development and is the same for FOXD1 ${ }^{+/ C r e} V H L^{f l / f l}$ and control kidneys. Data are expressed as means \pm SEM. $n=5$ kidneys per group. ${ }^{*} P<0.05$ versus control. AU, arbitrary unit.

in $\mathrm{FOXDI}^{+/ \mathrm{Cre}} \mathrm{VHL}^{f l f l}$ kidneys (Figure 4E). Expression levels of markers for distal convoluted tubules, such as solute carrier family 12 member 3 (SLC12A3; alias NCC), calbindin 1 , or transient receptor potential cation channel subfamily $\mathrm{V}$ member 5 , were as low as $20 \%$ of control kidneys (Figure 4F). The collecting duct system appeared less affected in the knockout kidneys. The expression of marker proteins for collecting ducts, such as sodium channel epithelial 1 (alias $\mathrm{ENaC}$ ), AQP2, or solute carrier family 14 member 2, transcript variant 4 (alias UT-A3), was less reduced in $\mathrm{FOXD1}^{+/ C r e} \mathrm{VHL}^{f / f l}$ kidneys (Figure 4F) compared to other tubular markers mentioned before.

\section{Differentiation Defects of Stromal Cells Are of Early} Developmental Onset, whereas Tubular Defects Result from Delayed Nephron Maturation

Time course analysis of gene expressions during kidney development indicated that renin expression as a marker for renin cell differentiation was reduced already at embryonic day 16 and remained at low levels during kidney development (Figure 6). Expression levels of integrin subunit $\alpha 8$ mRNA and smooth muscle myosin heavy polypeptide $11 \mathrm{mRNA}$ as markers for mesangial cells and vascular smooth muscle cells, respectively, continuously decreased during kidney development (Figure 6). mRNA expression levels of tubular markers, such as LRP2, uromodulin, or sodium channel epithelial $1 \alpha$ subunit (alias ENaC- $\alpha$ ) increased; however, this occurred with significant delay (Figure 6). Notably, EPO mRNA as a marker for tubulointerstitial cells increased continuously during kidney development (Figure 6).
Defects Caused by Deletion of VHL in Stroma Precursor Cells Require HIF2 but Not HIF1

$V H L$ deletion is known to stabilize the HIF transcription factors. ${ }^{36}$ To examine which of the above-mentioned changes of kidney development in FOXDI ${ }^{+/ C r e} V H L^{f / f l}$ mice were dependent on the HIF1 or HIF2 signaling pathway, we analyzed kidneys in which $V H L$ was codeleted with either HIF1A or HIF2A in the FoxD1 cell lineage. FOXD1 $1^{+/ C r e} V H L^{f l f l} H I F 1 A^{f l f l}$ mice behaved similar to FOXD1 $1^{+/ C r e} V H L^{f l f l}$ mice and died at approximately day 14 after birth (Figure 7A). Conversely, FOXD1 ${ }^{+/ C r e} V H L^{f / f l}$ $H I F 2 A^{f / A}$ mice were viable and reached adulthood (Figure 7A).

Gene Expression Pattern of Vascular, Juxtaglomerular, Interstitial, and Tubular Cells Normalizes after Codeletion of VHL and HIF2A

Gene expression analysis of kidneys of the different 7-dayold genotypes indicated that codeletion of $V H L$ with HIF2A led to an expression profile similar to that found in mice with intact $V H L\left(F O X D 1^{+/ C r e}\right.$ mice) in stromal precursors (Figure 8). The gene expression profile of kidneys with codeletion of VHL and HIFIA was similar to that found in mice with $V H L$ deletion $\left(F O X D 1^{+/ C r e} V H L^{f l / f}\right.$ mice) in stromal precursors (Figure 8). Of note, REN mRNA abundance and plasma REN concentrations (51.7 \pm 6.3 and $45.5 \pm 7.4 \mathrm{ng}$ angiotensin-I/hour per $\mathrm{mL}$ for $\mathrm{FOXD1^{+/Cre }}$ controls and for $F O X D 1^{+/ C r e} V H L^{f / f l} H I F 2 A^{f / f l}$ mice, respectively) were normal (Figures 8 and 9). Deletion of 

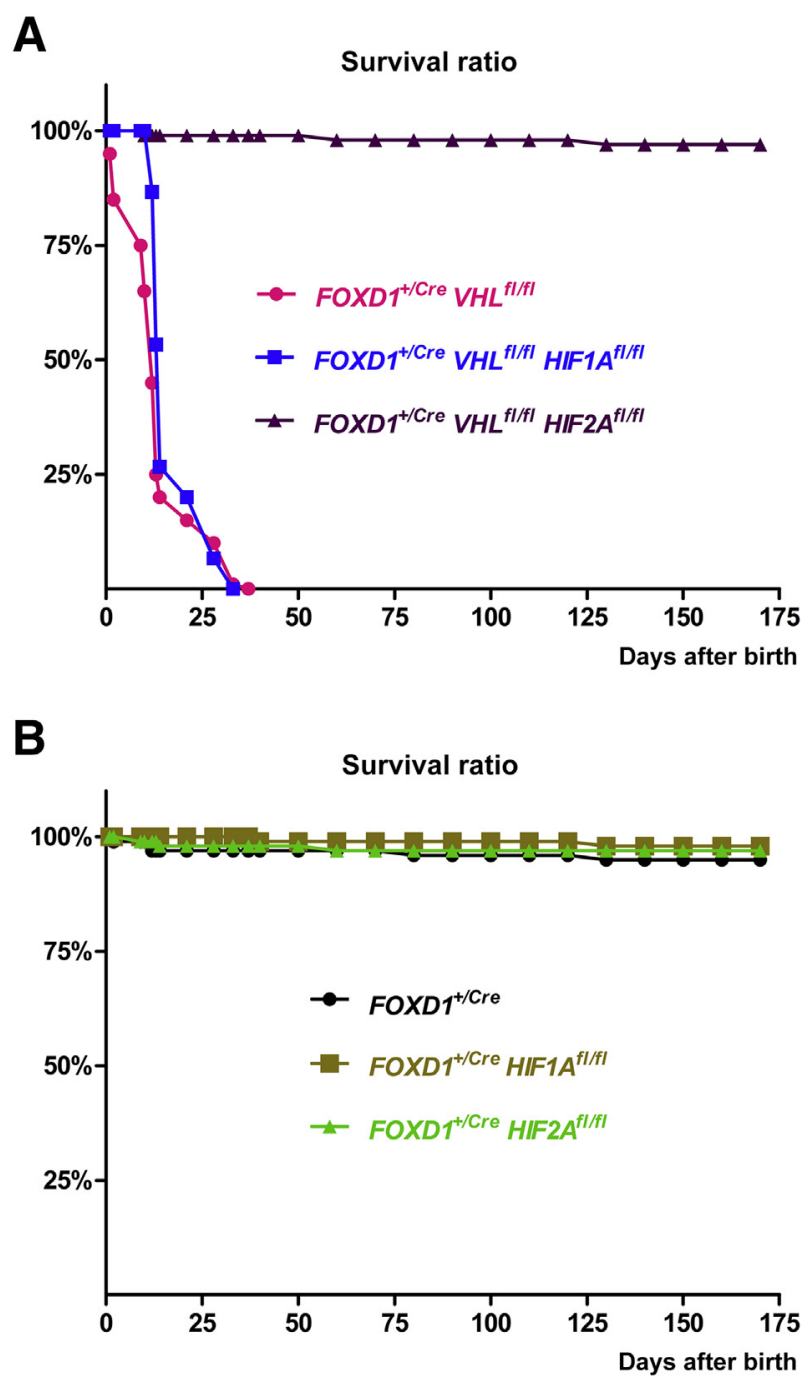

Figure 7 Survival rates in mice with and without deletions of VHL and HIFs in the stromal precursor cell line. Mice with deletion of VHL alone as well as mice with codeletion of VHL together with HIF1A or HIF2A (A), and mice with intact VHL and deletion of either HIF1A or HIF2A (B). Note that deletion of HIF2A but not of HIF1A rescues VHL-deficient mice, which all die within the first 3 weeks after birth. Deletion of either HIF1A or HIF2A in mice with intact $V H L$ in the stromal cell lineage exerts no influence on the normal survival of mice. Data are expressed as means \pm SEM. $n=30$ mice per group (A and $\mathbf{B})$.

$H I F 2 A$ in $F O X D 1^{+/ C r e} V H L^{f / f l}$ mice led to anemia, which was associated with subnormal plasma EPO concentrations and low kidney EPO mRNA expression levels (Figure 9). Codeletion of HIF 1A together with VHL in the FOXD1 cell lineage did not attenuate the stimulated EPO expression (Figure 9). A similar reduced EPO synthesis was also observed in mice lacking $H I F 2 A$ in the FOXD1 cell lineage with intact $V H L\left(F O X D 1^{+/ C r e} H I F 2 A^{f l / f l}\right.$ mice), whereas mice lacking HIFIA in the FOXD1 cell lineage with intact $V H L$ behaved normal in this regard (Figure 9).

Although FOXD1 $1^{+/ C r e} V H L^{f / f l} H I F 2 A^{f / f l}$ mice developed well and reached adulthood, they remained smaller than mice with intact $V H L$ and $H I F 2 A$ genes. Seven weeks after birth, the body weight of FOXD1 $1^{+/ C r e} V H L^{f / f l} H I F 2 A^{f l / f l}$ mice was reduced to $70 \%$ of controls, but relative kidney weight was normal (Table 5). Analysis of kidneys at day 7 (data not shown) and day 49 after birth revealed an almost normal histology (Figure 10).

The number of glomeruli was reduced in proportion to the body and kidney weights $(125 \pm 6$ and $75 \pm 4$ glomeruli per kidney cross section for 7-week-old controls and FOXDI $1^{+/ C r e} V H L^{f l / f} H I F 2 A^{f / f l}$ mice, respectively). mRNA expression levels for vascular, glomerular, interstitial, and tubular cell markers were almost normal in these kidneys (data not shown).

\section{Neither HIF1 nor HIF2 in Stromal Precursor Cells Is Required for Normal Kidney Development}

Deletion of HIF 1A or HIF2A alone in the FOXD1 cell lineage produced no apparent aberration of kidney histology (data not shown) and renal gene expression pattern (Figure 8), with the exception of low EPO mRNA expression levels in the case of HIF2A deletion (Figure 9). Accordingly, body weight gain (data not shown) and survival rate (Figure $7 \mathrm{~B}$ ) were not affected by deletion of HIFIA or HIF2A, at least for the observation period of 6 months.

\section{Possible Signals Involved in the Dedifferentiating Effects of VHL Deletion}

As a more unbiased approach to examine changes of renal gene expression induced by deletion of VHL from mesenchymal stromal precursors, we performed a whole transcriptome analysis of kidneys of $F O X D 1^{+/ C r e} V H L^{f / f l}$ mice at embryonic day 18 . Thresholds were set to $30 \%$ changes as a minimum and to significance levels of $P<0.01$. Under these restrictions, we identified 178 mRNAs that were upregulated (Supplemental Table S1) and 158 mRNAs that were down-regulated (Supplemental Table S2). Among the 12 most up-regulated mRNAs were genes known to be activated by the HIF signaling pathway, such as EPO, RGS4, adrenomedullin, prostaglandin-endoperoxide synthase 2 (alias COX2), and transmembrane protein $45 \mathrm{~A}$ (Table 6). The 10 most down-regulated genes comprised marker genes for renin cells, such as REN and aldo-keto reductase family 1 , member $\mathrm{B} 7$, but also markers for tubular cells (Table 7). Of note was the down-regulation of gasdermin, which is considered to affect epithelial differentiation, ${ }^{37,38}$ but which has yet not been considered in a renal context. Because the WNT signaling and the Notch signaling pathways are thought to be of major importance for kidney development and differentiation, ${ }^{39-44}$ we analyzed the embryonic day 18 kidney transcriptome with regard to key components of these pathways. Although we found no differential expression for Notch receptors and their ligands, components of the WNT signaling pathway, such as dickkopf WNT signaling pathway inhibitor 1, WNT1 inducible signaling pathway protein 1 , and Wnt family member 11, were down-regulated (Supplemental 

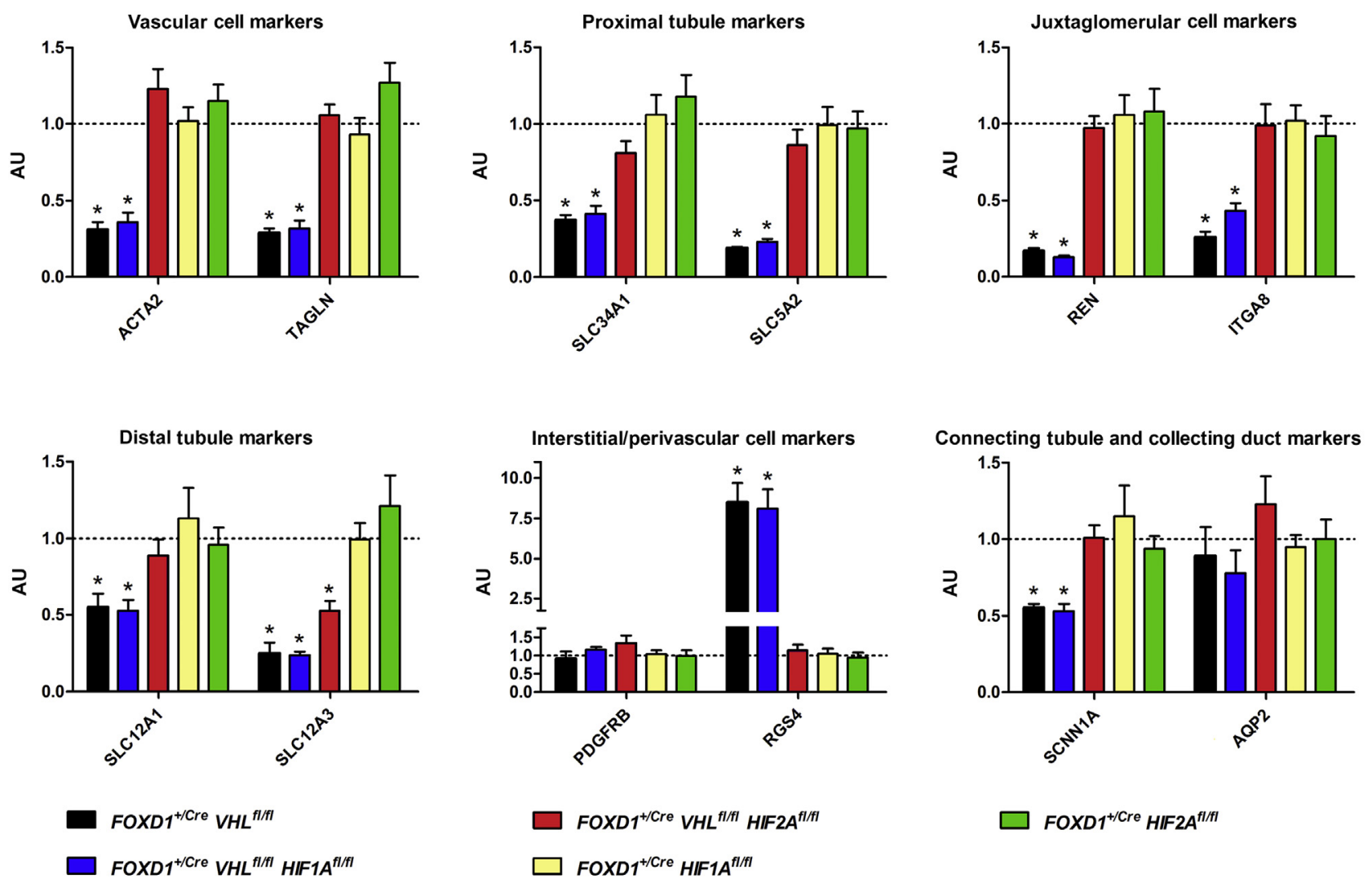

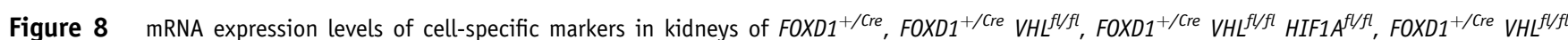
HIF2A $A^{f l / f l}, F O X D 1^{+/ C r e} H I F 1 A^{f l / f l}$, and FOXD1 ${ }^{+/ C r e} H I F 2 A^{f l / f l}$ mice. mRNA abundance of markers for smooth muscle cells [ACTA2 and transgelin (TAGLN)], for juxtaglomerular and mesangial cells [REN and integrin subunit $\alpha 8$ (ITGA8)], as well as for interstitial pericyte-like cells [platelet-derived growth factor receptor $\beta$ (PDGFRB) and RGS4] and for markers for proximal tubules (SLC34A1 and SLC5A2), distal tubules [solute carrier family 12 member 1 (SLC12A1) and SLC12A3], and connecting tubules/collecting ducts [sodium channel epithelial $1 \alpha$ subunit (SCNN1A) and AQP2]. mRNA expression levels of the FOXD1 ${ }^{+/ C r e}$ control litters are set to 1 (dashed lines) and serve as a reference. Ribosomal protein L32 was used as a control. Of note, all genotypes were 7 days old, when kidneys were removed. Data are expressed as means \pm SEM. $n=8$ kidneys per group. ${ }^{*} P<0.05$ versus FOXD1 ${ }^{+/ C r e}$ control litters. AU, arbitrary unit; SLC5A2, solute carrier family 5 member 2; SLC34A1, solute carrier family 34 member 1.

Table S3). Furthermore, other important regulators of kidney development and differentiation, such as factors of the glial-cell derived neurotrophic factor/ret proto-oncogene, hepatocyte growth factor/met proto-oncogene, and bone morphogenetic protein signaling pathways, were affected in their mRNA expression levels (Supplemental Table S3). Notably, the expression of decorin, which has been described as a potent inhibitor of tubule differentiation, ${ }^{45}$ was clearly down-regulated by $V H L$ deletion in the stromal progenitor cell lineage (Supplemental Table S2).

\section{Discussion}

The central finding of this study is that activation of the hypoxia signaling caused by deletion of the ubiquitin-ligase $V H L$ in stromal progenitors impairs kidney differentiation and maturation, leading to renal insufficiency being the most likely reason for the early postnatal death. This effect is particular, because deletion of $V H L$ from tubular ${ }^{10}$ or collecting duct progenitors, ${ }^{11}$ as well as from differentiated tubular and collecting duct cells allows viability. ${ }^{32,46-49}$
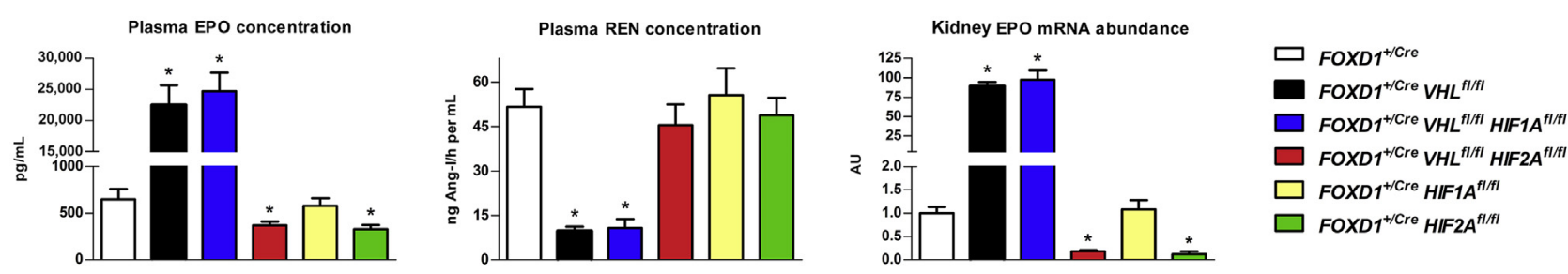

Figure 9 Plasma EPO concentrations, kidney EPO mRNA abundance, and plasma REN concentrations of 7-day-old mice with the genotypes FOXD1 ${ }^{+/ C r e}$,

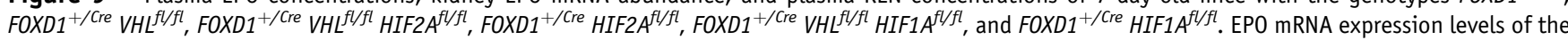
FOXD $1^{+/ C r e}$ control mice are set to 1 and serve as a reference. Ribosomal protein L32 was used as a control. Data are expressed as means \pm SEM. $n=5$ kidneys per group. ${ }^{*} P<0.05$ versus control. Ang-I, angiotensin-I; AU, arbitrary unit. 


\begin{tabular}{|c|c|c|c|c|}
\hline Parameter & FOXD1 ${ }^{+/ C r e}$ & FOXD1 $1^{+/ C r e} V H L^{f l / f l} H I F 2 A^{f l / f l}$ & FOXD1 ${ }^{+/ C r e} H I F 2 A^{f l / f l}$ & $\mathrm{FOXD1}^{+/ C r e} \mathrm{HIF1A}^{f l / f l}$ \\
\hline Body weight, g & $20.3 \pm 0.4$ & $14.2 \pm 0.6^{*}$ & $19.5 \pm 0.5^{\dagger}$ & $19.9 \pm 0.7$ \\
\hline
\end{tabular}

Body weight and relative kidney weight of 7-week-old female mice. Data are expressed as means \pm SEM. $n=6$ mice per group.

${ }^{*} P$ value related to $F O X D 1^{+/ C r e}$ mice.

${ }^{\dagger} P$ value related to $F O X D 1^{+/ C r e} V H L^{f l / f l} H I F 2 A^{f l / f l}$ mice.

Because VHL deletion in stromal precursors increased HIF2A protein abundance and because renal effects induced by $V H L$ deletion were absent when HIF $2 A$ was codeleted from stromal precursors, we assume that the effects observed in the present study were mainly caused by stable HIF2 activation in renal stromal precursor cells and not by the lack of the VHL protein itself. This conclusion is supported by recently published data showing juvenile lethality of mice with combined inactivation of the prolyl 4-hydroxylases $P 4 H 2$ and $P 4 H 3$ in the FOXD1 cell lineage, which results in the activation of HIF2. ${ }^{15}$ In consequence, these findings would suggest that states of chronic hypoxia in stromal cells during kidney development may exert similar negative effects on kidney maturation. In this context, two main aspects can be distinguished. One is that activation of HIF2 (induced by $V H L$ deletion) in stromal precursors probably directly inhibited the differentiation of cell types arising from stromal cells, such as vascular smooth muscle cells, renin cells, and mesangial cells. The findings suggesting that HIF2 activation in renal stromal progenitors prevented differentiation of renin cells thus completed our previous observations, suggesting that constitutive and inducible activation of the HIF2 signaling pathway in renin-expressing cells led to a retransformation of the cells into a more immature stromal cell type capable of producing EPO. ${ }^{50}$ In addition, the differentiation of stromal precursor cells into vascular smooth muscle cells appeared to be impaired, as indicated by the development of thin smooth muscle cells, which probably cannot sufficiently resist the intravascular blood pressure leading to a widened lumen of intrarenal arterioles. The development of the endothelium and the gross architecture of the preglomerular vascular tree with its characteristic vessel branching appeared to be less affected. Similarly, also a more specialized differentiation of mesangial cells, as indicated by the expression of integrin subunit $\alpha 8^{51-53}$ and gap junction protein $\alpha$ $5,{ }^{53-56}$ was impaired HIF2 dependently by $V H L$ deletion in stromal precursors. The expression of platelet-derived growth factor receptor $\beta$ by mesangial cells appeared normal, suggesting that mesangial cell precursors had properly invaded developing glomeruli. In line, podocyte development appeared normal and also the average volume of glomeruli was normal. Altogether, these findings suggest that HIF2 activation impairs stromal differentiation rather than stromal development.

The more undifferentiated stages of stromal cells, such as the interstitial pericyte-like cells, appeared maintained, as indicated by the normal expression pattern of structural markers that are commonly attributed to these cells, such as platelet-derived growth factor receptor $\beta$, chondroitin sulfate proteoglycan 4, NT5E, or RGS proteins. ${ }^{7,57-60}$ The increased expression of NTSE and RGS4 is likely a direct transcriptional effect of HIF2 on these genes. ${ }^{61}$ Interstitial cells are also considered as the physiological site of renal EPO production. ${ }^{62,63}$ In line, EPO expression was strongly enhanced by $V H L$ deletion in stromal precursors ${ }^{15}$ in a strict dependency on HIF2 but not on HIF1; this is also in

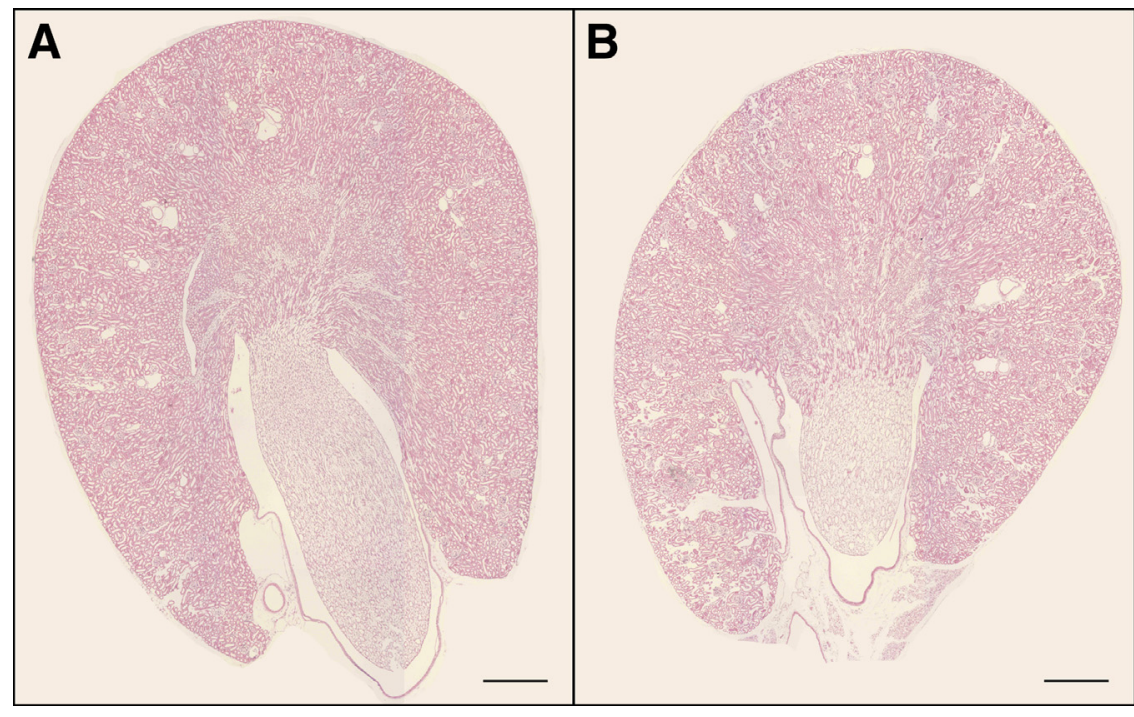

Figure 10 The additional deletion of HIF2A rescues the FOXD1 $1^{+/ C r e} V H L^{f l f l}$ genotype from early postnatal death. Overview sections of kidneys from a control (A) and a FOXD1 ${ }^{+/ C r e}$ VHL $L^{f l f l} H I F 2 A^{f / f l}$ (B) mouse at day 45 after birth. Scale bars $=300$ $\mu \mathrm{m}$ (A and $\mathbf{B})$. 
Table 6 Up-Regulated Genes in FOXD1 ${ }^{+/ C r e}$ VHL $L^{f l f l}$ E18 Kidneys

\begin{tabular}{|c|c|c|c|}
\hline \multirow[b]{2}{*}{ Fold change } & \multicolumn{2}{|l|}{ Gene } & \multirow[b]{2}{*}{$P$ value } \\
\hline & Full name & Symbol & \\
\hline 5.42 & Erythropoietin & $\underline{E P O}$ & $3.15 \times 10^{-7}$ \\
\hline 4.78 & Complement C7 & $\overline{C 7}$ & $1.45 \times 10^{-4}$ \\
\hline 3.96 & $\alpha$-2-macroglobulin & $A 2 M$ & $1.20 \times 10^{-6}$ \\
\hline 3.86 & Adrenomedullin & $A D M$ & $5.91 \times 10^{-7}$ \\
\hline 2.95 & Prostaglandin-endoperoxide synthase 2 & PTGS2 & $2.23 \times 10^{-4}$ \\
\hline 2.93 & Solute carrier family 2 member 3 & $\overline{S L C 2 A 3}$ & $1.89 \times 10^{-5}$ \\
\hline 2.78 & $\begin{array}{l}\text { NDUFA4, mitochondrial complex } \\
\text { associated like } 2\end{array}$ & NDUFA 4 L2 & $9.49 \times 10^{-7}$ \\
\hline 2.41 & Pappalysin 2 & PAPPA2 & $7.61 \times 10^{-5}$ \\
\hline
\end{tabular}

Twelve most up-regulated mRNAs in kidneys of $F O X D 1^{+/ C r e} V H L^{f l f l}$ mice at E18 compared to FOXD1 ${ }^{+/ C r e}$ control kidneys. Underlined genes are known to be stimulated by the hypoxia signaling pathway.

E18, embryonic day 18.

accordance with the central role of HIF2 for regulating EPO production. ${ }^{64,65}$ Because deletion of HIF2A from stromal precursors led to subnormal EPO production and prevented any increase of renal EPO expression in response to the developing anemia, we would infer that renal EPO-producing cells almost exclusively derive from the FOXD1-positive precursor compartment. ${ }^{66}$ Interstitial pericyte-like cells are also considered as a major source of myofibroblast progenitors contributing to renal fibrosis. ${ }^{7,67}$ It may be of clinical relevance therefore that activation of the HIF2 signaling pathway in stromal precursors did not shift these cells into a more profibrotic phenotype. Although

Table 7 Down-Regulated Genes in FOXD1 $1^{+/ C r e}$ VHL $L^{f l f l}$ E18 Kidneys

\begin{tabular}{|c|c|c|c|}
\hline \multirow{2}{*}{$\begin{array}{l}\text { Fold } \\
\text { change }\end{array}$} & \multicolumn{2}{|l|}{ Gene } & \multirow[b]{2}{*}{$P$ value } \\
\hline & Full name & Symbol & \\
\hline-4.42 & Renin & REN & $2.54 \times 10^{-5}$ \\
\hline-3.30 & Glutathione peroxidase 6 & GPX6 & $2.09 \times 10^{-4}$ \\
\hline-2.95 & Gasdermin C2 & GSDMC2 & $4.47 \times 10^{-4}$ \\
\hline-2.70 & $\begin{array}{l}\text { Chemokine (C-X-C motif) } \\
\text { ligand } 13\end{array}$ & CCL13 & $3.27 \times 10^{-5}$ \\
\hline-2.68 & Gasdermin C3 & GSDMC3 & $9.69 \times 10^{-3}$ \\
\hline-2.65 & $\begin{array}{l}\text { Aldo-keto reductase family } 1 \text {, } \\
\text { member B7 }\end{array}$ & $A K R 1 B 7$ & $8.48 \times 10^{-4}$ \\
\hline-2.56 & $\begin{array}{l}\text { Hydroxy- } \delta \text {-5-steroid } \\
\text { dehydrogenase, } 3 \beta \text { - and } \\
\text { steroid } \delta \text {-isomerase } 6\end{array}$ & HSD3B6 & $6.30 \times 10^{-4}$ \\
\hline-2.52 & Uromodulin & $U M O D$ & $1.54 \times 10^{-4}$ \\
\hline-2.19 & $\begin{array}{l}\text { Prostaglandin E receptor } 3 \\
\text { (subtype EP3) }\end{array}$ & PTGER3 & $1.46 \times 10^{-4}$ \\
\hline-2.09 & Aquaporin 6 & $A Q P 6$ & $1.82 \times 10^{-3}$ \\
\hline
\end{tabular}

Ten most down-regulated mRNAs in kidneys of $F O X D 1^{+/ C r e} V H L^{f l / f l}$ mice at E18 compared to FOXD1 $1^{+/ C r e}$ control kidneys.

E18, embryonic day 18. our data do not allow us to provide an explanation about which pathways HIF2 stabilization could inhibit the functional maturation of stroma cells, they do support the concept that HIF2 exerts a dedifferentiating rather than a differentiating effect in cells. ${ }^{67-70}$

The second major aspect of our study is that FOXD1driven deletion of $V H L$ in stromal progenitors also impaired nephrogenesis, including functional maturation of tubules, and that this detrimental effect could again be prevented by deletion of HIF2A. A similar observation has been made previously in zebra fish using HIF2-inhibiting peptide. ${ }^{71}$ Because tubular cells do not belong to the FOXD1 cell lineage, we assume, in accordance with previous findings, that stroma (precursor) cells exert influence on the differentiation of nephrons from the metanephric mesenchyme. ${ }^{72}$ In line with such a role of the renal stroma for tubulogenesis is a recent report that inhibition of miRNA formation by deletion of dicer in renal stromal progenitors inhibits kidney development by inhibiting tubule formation from the metanephric mesenchyme. ${ }^{73}$ The phenotype induced by $V H L$ deletion, as observed in our study, however, was not as severe as that achieved with dicer deletion. Kidney mass was reduced in proportion to the number of nephrons, as indicated by the number of developed glomeruli. Because the expression levels of specific components of the WNT-, glial-cell derived neurotrophic factor/Ret-, and bone morphogenetic protein-signaling pathways were downregulated, the reduced number of nephrons and glomeruli might arise from a reduced number of branching of the developing collecting duct system. ${ }^{73-77}$ An impaired nephron endowment or vascular defects could also explain the reduced formation of nephrons. More extensive histological analyses will be required to define the mechanisms leading to the reduced number of nephrons. In addition to the reduced formation of the nephrons, the functional 
maturation of specific nephron segments was impaired. From changes of gross morphology and nephron segment marker protein expression, it appeared as if the differentiation/maturation of cortical tubules was more affected in FOXD1 $1^{+/ C r e} V_{H L}{ }^{f / f l}$ kidneys than the differentiation of the collecting duct system. This observation fits with previous findings that the developing stroma essentially influences the differentiation of tubules from the metanephric mesenchyme and that the effect on cortical and medullary differentiation can be different. ${ }^{35}$ How and along which pathways the stroma exerts this effect are poorly understood. A role of decorin, which has recently been identified as an inhibiting paracrine regulator of tubule differentiation, ${ }^{45}$ appears less likely, because it was strongly down-regulated in kidneys with $V H L$ deletion. Another pathway that could lead to maturation defects is the down-regulation of hepatocyte growth factor expression, which is considered important for tubular differentiation and maturation. ${ }^{78-80}$ It is also conceivable that the tubular maturation defects could be related to the suppression of renin expression observed in $F O X D 1^{+/ C r e} V H L^{f / f l}$ kidneys, because REN is required for normal kidney development. In humans, defects of the renin-angiotensin-aldosterone system inhibit tubular maturation, leading to nonfunctional kidneys and perinatal death, known as Potter-like syndrome. ${ }^{81,82}$ Deletion of the Renlc gene in mice is associated with kidney malfunction, leading to early perinatal death. ${ }^{81}$ Although the kidney phenotype of Renlc defective mice is somewhat different from that of FOXD1 $1^{+/ C r e} V H L^{f / f l}$ mice, it cannot be excluded that the suppression of REN expression at least contributes to the maturation defect of tubules as it is strikingly evident in fetal human kidneys. ${ }^{82}$ Finally, it is also conceivable that the maturation deficits of vascular smooth muscle cells disturb renal perfusion and the supply of the renal cortex with nutrients.

Altogether, our findings suggest that among the three main cell compartments that produce the developing kidney, hypoxia may exert detrimental effects on nephrogenesis in the stroma progenitor compartment.

\section{Acknowledgments}

We thank Gerda Treuner, Rosmarie Heydn, Brigitte Rogge, Ramona Steppan, and Anna M'Bangui for technical assistance.

\section{Supplemental Data}

Supplemental material for this article can be found at http://dx.doi.org/10.1016/j.ajpath.2017.03.014.

\section{References}

1. Buchholz B, Schley G, Eckardt KU: The impact of hypoxia on nephrogenesis. Curr Opin Nephrol Hypertens 2016, 25:180-186
2. Hemker SL, Sims-Lucas S, Ho J: Role of hypoxia during nephrogenesis. Pediatr Nephrol 2016, 31:1571-1577

3. Figueroa H, Lozano M, Suazo C, Eixarch E, Illanes SE, Carreno JE, Villanueva S, Hernandez-Andrade E, Gratacos E, Irarrazabal CE: Intrauterine growth restriction modifies the normal gene expression in kidney from rabbit fetuses. Early Hum Dev 2012, 88:899-904

4. Lueder FL, Kim SB, Buroker CA, Bangalore SA, Ogata ES: Chronic maternal hypoxia retards fetal growth and increases glucose utilization of select fetal tissues in the rat. Metabolism 1995, 44: $532-537$

5. Mao C, Hou J, Ge J, Hu Y, Ding Y, Zhou Y, Zhang H, Xu Z, Zhang L: Changes of renal AT1/AT2 receptors and structures in ovine fetuses following exposure to long-term hypoxia. Am J Nephrol 2010, 31:141-150

6. Li W, Hartwig S, Rosenblum ND: Developmental origins and functions of stromal cells in the normal and diseased mammalian kidney. Dev Dyn 2014, 243:853-863

7. Humphreys BD, Lin SL, Kobayashi A, Hudson TE, Nowlin BT, Bonventre JV, Valerius MT, McMahon AP, Duffield JS: Fate tracing reveals the pericyte and not epithelial origin of myofibroblasts in kidney fibrosis. Am J Pathol 2010, 176:85-97

8. Duffield JS: Cellular and molecular mechanisms in kidney fibrosis. J Clin Invest 2014, 124:2299-2306

9. Schley G, Scholz H, Kraus A, Hackenbeck T, Klanke B, Willam C, Wiesener MS, Heinze E, Burzlaff N, Eckardt KU, Buchholz B: Hypoxia inhibits nephrogenesis through paracrine Vegfa despite the ability to enhance tubulogenesis. Kidney Int 2015, 88:1283-1292

10. Wang SS, Gu YF, Wolff N, Stefanius K, Christie A, Dey A, Hammer RE, Xie XJ, Rakheja D, Pedrosa I, Carroll T, McKay RM, Kapur P, Brugarolas J: Bap1 is essential for kidney function and cooperates with Vhl in renal tumorigenesis. Proc Natl Acad Sci U S A 2014, 111:16538-16543

11. Pritchett TL, Bader HL, Henderson J, Hsu T: Conditional inactivation of the mouse von Hippel-Lindau tumor suppressor gene results in wide-spread hyperplastic, inflammatory and fibrotic lesions in the kidney. Oncogene 2014, 34:2631-2639

12. Kimura K, Iwano M, Higgins DF, Yamaguchi Y, Nakatani K, Harada K, Kubo A, Akai Y, Rankin EB, Neilson EG, Haase VH, Saito Y: Stable expression of HIF-1alpha in tubular epithelial cells promotes interstitial fibrosis. Am J Physiol Renal Physiol 2008, 295 : F1023-F1029

13. Hatini V, Huh SO, Herzlinger D, Soares VC, Lai E: Essential role of stromal mesenchyme in kidney morphogenesis revealed by targeted disruption of Winged Helix transcription factor BF-2. Genes Dev 1996, 10:1467-1478

14. Hum S, Rymer C, Schaefer C, Bushnell D, Sims-Lucas S: Ablation of the renal stroma defines its critical role in nephron progenitor and vasculature patterning. PLoS One 2014, 9:e88400

15. Kobayashi H, Liu Q, Binns TC, Urrutia AA, Davidoff O, Kapitsinou PP, Pfaff AS, Olauson H, Wernerson A, Fogo AB, Fong GH, Gross KW, Haase VH: Distinct subpopulations of FOXD1 stroma-derived cells regulate renal erythropoietin. J Clin Invest 2016, 126:1926-1938

16. Rauner M, Franke K, Murray M, Singh RP, Hiram-Bab S, Platzbecker U, Gassmann M, Socolovsky M, Neumann D, Gabet Y, Chavakis T, Hofbauer LC, Wielockx B: Increased EPO levels are associated with bone loss in mice lacking PHD2 in EPO-producing cells. J Bone Miner Res 2016, 31:1877-1887

17. Wu K, Zhou KL, Wang YL, Zhou YF, Tian NF, Wu YS, Chen DH, Zhang D, Wang XY, Xu HZ, Zhang XL: Stabilization of HIF-1 alpha by FG-4592 promotes functional recovery and neural protection in experimental spinal cord injury. Brain Res 2016, 1632:19-26

18. Myllymaki MN, Maatta J, Dimova EY, Izzi V, Vaisanen T, Myllyharju J, Koivunen P, Serpi R: Notch downregulation and extramedullary erythrocytosis in HIF prolyl 4-hydroxylase 2-deficient mice. Mol Cell Biol 2017, 37. e00529-16

19. Schley G, Klanke B, Schodel J, Kroning S, Turkoglu G, Beyer A, Hagos Y, Amann K, Burckhardt BC, Burzlaff N, Eckardt KU, 
Willam C: Selective stabilization of HIF-1alpha in renal tubular cells by 2-oxoglutarate analogues. Am J Pathol 2012, 181:1595-1606

20. Bernhardt WM, Warnecke C, Willam C, Tanaka T, Wiesener MS, Eckardt KU: Organ protection by hypoxia and hypoxia-inducible factors. Methods Enzymol 2007, 435:221-245

21. Nangaku M: Novel therapeutic approach targeting the HIF-HRE system in the kidney. Adv Exp Med Biol 2009, 645:81-86

22. Maxwell PH, Wiesener MS, Chang GW, Clifford SC, Vaux EC, Cockman ME, Wykoff CC, Pugh CW, Maher ER, Ratcliffe PJ: The tumour suppressor protein VHL targets hypoxia-inducible factors for oxygen-dependent proteolysis. Nature 1999, 399:271-275

23. Haase VH: The VHL tumor suppressor: master regulator of HIF. Curr Pharm Des 2009, 15:3895-3903

24. Committee for the Update of the Guide for the Care and Use of Laboratory Animals; National Research Council: Guide for the Care and Use of Laboratory Animals. Eighth Edition. Washington, DC, National Academies Press, 2011

25. Haase VH, Glickman JN, Socolovsky M, Jaenisch R: Vascular tumors in livers with targeted inactivation of the von Hippel-Lindau tumor suppressor. Proc Natl Acad Sci U S A 2001, 98:1583-1588

26. Kobayashi A, Mugford JW, Krautzberger AM, Naiman N, Liao J, McMahon AP: Identification of a multipotent self-renewing stromal progenitor population during mammalian kidney organogenesis. Stem Cell Reports 2014, 3:650-662

27. Gruber M, Hu CJ, Johnson RS, Brown EJ, Keith B, Simon MC: Acute postnatal ablation of Hif-2 alpha results in anemia. Proc Natl Acad Sci U S A 2007, 104:2301-2306

28. Ryan HE, Poloni M, McNulty W, Elson D, Gassmann M, Arbeit JM, Johnson RS: Hypoxia-inducible factor-1alpha is a positive factor in solid tumor growth. Cancer Res 2000, 60:4010-4015

29. Muzumdar MD, Tasic B, Miyamichi K, Li L, Luo L: A global double-fluorescent cre reporter mouse. Genesis 2007, 45:593-605

30. Schweda F, Wagner C, Kramer BK, Schnermann J, Kurtz A: Preserved macula densa-dependent renin secretion in $\mathrm{A}(1)$ adenosine receptor knockout mice. Am J Physiol Renal Physiol 2003, 284: F770-F777

31. Chomczynski P, Sacchi N: Single-step method of RNA isolation by acid guanidinium thiocyanate phenol chloroform extraction. Anal Biochem 1987, 162:156-159

32. Schley G, Klanke B, Schodel J, Forstreuter F, Shukla D, Kurtz A, Amann K, Wiesener MS, Rosen S, Eckardt KU, Maxwell PH, Willam C: Hypoxia-inducible transcription factors stabilization in the thick ascending limb protects against ischemic acute kidney injury. J Am Soc Nephrol 2011, 22:2004-2015

33. Rosenberger C, Mandriota S, Jurgensen JS, Wiesener MS, Horstrup JH, Frei U, Ratcliffe PJ, Maxwell PH, Bachmann S, Eckardt KU: Expression of hypoxia-inducible factor-1alpha and -2alpha in hypoxic and ischemic rat kidneys. J Am Soc Nephrol 2002, 13:1721-1732

34. Sauter A, Machura K, Neubauer B, Kurtz A, Wagner C: Development of renin expression in the mouse kidney. Kidney Int 2008, $73: 43-51$

35. Hendry C, Rumballe B, Moritz K, Little MH: Defining and redefining the nephron progenitor population. Pediatr Nephrol 2011, 26: $1395-1406$

36. Kapitsinou PP, Haase VH: The VHL tumor suppressor and HIF: insights from genetic studies in mice. Cell Death Differ 2008, 15: $650-659$

37. Saeki N, Usui T, Aoyagi K, Kim DH, Sato M, Mabuchi T, Yanagihara K, Ogawa K, Sakamoto H, Yoshida T, Sasaki H: Distinctive expression and function of four GSDM family genes (GSDMA-D) in normal and malignant upper gastrointestinal epithelium. Genes Chromosomes Cancer 2009, 48:261-271

38. Tamura M, Shiroishi T: GSDM family genes meet autophagy. Biochem J 2015, 469:e5-e7

39. McCright B, Gao X, Shen L, Lozier J, Lan Y, Maguire M, Herzlinger D, Weinmaster G, Jiang R, Gridley T: Defects in development of the kidney, heart and eye vasculature in mice homozygous for a hypomorphic Notch2 mutation. Development 2001, 128: 491-502

40. Xue Y, Gao X, Lindsell CE, Norton CR, Chang B, Hicks C, Gendron-Maguire M, Rand EB, Weinmaster G, Gridley T: Embryonic lethality and vascular defects in mice lacking the Notch ligand Jagged1. Hum Mol Genet 1999, 8:723-730

41. Cheng HT, Kim M, Valerius MT, Surendran K, Schuster-Gossler K, Gossler A, McMahon AP, Kopan R: Notch2, but not Notch1, is required for proximal fate acquisition in the mammalian nephron. Development 2007, 134:801-811

42. Kamath BM, Podkameni G, Hutchinson AL, Leonard LD, Gerfen J, Krantz ID, Piccoli DA, Spinner NB, Loomes KM, Meyers K: Renal anomalies in Alagille syndrome: a disease-defining feature. Am J Med Genet A 2012, 158A:85-89

43. Kispert A, Vainio S, McMahon AP: Wnt-4 is a mesenchymal signal for epithelial transformation of metanephric mesenchyme in the developing kidney. Development 1998, 125:4225-4234

44. Carroll TJ, Park JS, Hayashi S, Majumdar A, McMahon AP: Wnt9b plays a central role in the regulation of mesenchymal to epithelial transitions underlying organogenesis of the mammalian urogenital system. Dev Cell 2005, 9:283-292

45. Fetting JL, Guay JA, Karolak MJ, Iozzo RV, Adams DC, Maridas DE, Brown AC, Oxburgh L: FOXD1 promotes nephron progenitor differentiation by repressing decorin in the embryonic kidney. Development 2014, 141:17-27

46. Rankin EB, Tomaszewski JE, Haase VH: Renal cyst development in mice with conditional inactivation of the von Hippel-Lindau tumor suppressor. Cancer Res 2006, 66:2576-2583

47. Fahling M, Mathia S, Paliege A, Koesters R, Mrowka R, Peters H, Persson PB, Neumayer HH, Bachmann S, Rosenberger C: Tubular von Hippel-Lindau knockout protects against rhabdomyolysisinduced AKI. J Am Soc Nephrol 2013, 24:1806-1819

48. Mathia S, Paliege A, Koesters R, Peters H, Neumayer HH, Bachmann S, Rosenberger C: Action of hypoxia-inducible factor in liver and kidney from mice with Pax8-rtTA-based deletion of von Hippel-Lindau protein. Acta Physiol (Oxf) 2013, 207: $565-576$

49. Farsijani NM, Liu Q, Kobayashi H, Davidoff O, Sha F, Fandrey J, Ikizler TA, O'Connor PM, Haase VH: Renal epithelium regulates erythropoiesis via HIF-dependent suppression of erythropoietin. J Clin Invest 2016, 126:1425-1437

50. Kurt B, Gerl K, Karger C, Schwarzensteiner I, Kurtz A: Chronic hypoxia-inducible transcription factor-2 activation stably transforms juxtaglomerular renin cells into fibroblast-like cells in vivo. J Am Soc Nephrol 2015, 26:587-596

51. Hartner A, Schocklmann H, Prols F, Muller U, Sterzel RB: Alpha8 integrin in glomerular mesangial cells and in experimental glomerulonephritis. Kidney Int 1999, 56:1468-1480

52. Starke C, Betz H, Hickmann L, Lachmann P, Neubauer B, Kopp JB, Sequeira-Lopez ML, Gomez RA, Hohenstein B, Todorov VT, Hugo CP: Renin lineage cells repopulate the glomerular mesangium after injury. J Am Soc Nephrol 2015, 26:48-54

53. Gerl K, Miquerol L, Todorov VT, Hugo CP, Adams RH, Kurtz A, Kurt B: Inducible glomerular erythropoietin production in the adult kidney. Kidney Int 2015, 88:1345-1355

54. Kurtz L, Madsen K, Kurt B, Jensen BL, Walter S, Banas B, Wagner C, Kurtz A: High-level connexin expression in the human juxtaglomerular apparatus. Nephron Physiol 2010, 116:p1-p8

55. Hwan Seul K, Beyer EC: Heterogeneous localization of connexin 40 in the renal vasculature. Microvasc Res 2000, 59:140-148

56. Morioka T, Okada S, Nameta M, Kamal F, Yanakieva-Georgieva NT, Yao J, Sato A, Piao H, Oite T: Glomerular expression of connexin 40 and connexin 43 in rat experimental glomerulonephritis. Clin Exp Nephrol 2013, 17:191-204

57. Humphreys BD: Targeting pericyte differentiation as a strategy to modulate kidney fibrosis in diabetic nephropathy. Semin Nephrol 2012, 32:463-470 
58. Kida Y, Duffield JS: Pivotal role of pericytes in kidney fibrosis. Clin Exp Pharmacol Physiol 2011, 38:467-473

59. Cho H, Kozasa T, Bondjers C, Betsholtz C, Kehrl JH: Pericyte-specific expression of Rgs5: implications for PDGF and EDG receptor signaling during vascular maturation. FASEB J 2003, 17:440-442

60. Bondjers C, Kalen M, Hellstrom M, Scheidl SJ, Abramsson A, Renner O, Lindahl P, Cho H, Kehrl J, Betsholtz C: Transcription profiling of platelet-derived growth factor-B-deficient mouse embryos identifies RGS5 as a novel marker for pericytes and vascular smooth muscle cells. Am J Pathol 2003, 162:721-729

61. Olechnowicz SWZ, Fedele AO, Peet DJ: Hypoxic induction of the regulator of G-protein signalling 4 gene is mediated by the hypoxiainducible factor pathway. PLoS One 2012, 7:e44564

62. Bachmann S, Le Hir M, Eckardt KU: Co-localization of erythropoietin mRNA and ecto-5'-nucleotidase immunoreactivity in peritubular cells of rat renal cortex indicates that fibroblasts produce erythropoietin. J Histochem Cytochem 1993, 41:335-341

63. Maxwell PH, Osmond MK, Pugh CW, Heryet A, Nicholls LG, Tan CC, Doe BG, Ferguson DJ, Johnson MH, Ratcliffe PJ: Identification of the renal erythropoietin-producing cells using transgenic mice. Kidney Int 1993, 44:1149-1162

64. Paliege A, Rosenberger C, Bondke A, Sciesielski L, Shina A, Heyman SN, Flippin LA, Arend M, Klaus SJ, Bachmann S: Hypoxiainducible factor-2alpha-expressing interstitial fibroblasts are the only renal cells that express erythropoietin under hypoxia-inducible factor stabilization. Kidney Int 2010, 77:312-318

65. Rankin EB, Biju MP, Liu Q, Unger TL, Rha J, Johnson RS, Simon MC, Keith B, Haase VH: Hypoxia-inducible factor-2 (HIF-2) regulates hepatic erythropoietin in vivo. J Clin Invest 2007, 117:1068-1077

66. Obara N, Suzuki N, Kim K, Nagasawa T, Imagawa S, Yamamoto M: Repression via the GATA box is essential for tissue-specific erythropoietin gene expression. Blood 2008, 111:5223-5232

67. Bhaskara VK, Mohanam I, Rao JS, Mohanam S: Intermittent hypoxia regulates stem-like characteristics and differentiation of neuroblastoma cells. PLoS One 2012, 7:e30905

68. Pietras A, Johnsson AS, Pahlman S: The HIF-2 alpha-driven pseudohypoxic phenotype in tumor aggressiveness, differentiation, and vascularization. Curr Top Microbiol Immunol 2010, 345:1-20

69. Pietras A, Hansford LM, Johnsson AS, Bridges E, Sjolund J, Gisselsson D, Rehn M, Beckman S, Noguera R, Navarro S, Cammenga J, Fredlund E, Kaplan DR, Pahlman S: HIF-2 alpha maintains an undifferentiated state in neural crest-like human neuroblastoma tumor-initiating cells. Proc Natl Acad Sci U S A 2009, 106:16805-16810

70. Covello KL, Kehler J, Yu HW, Gordan JD, Arsham AM, Hu CJ, Labosky PA, Simon MC, Keith B: HIF-2 alpha regulates Oct-4: effects of hypoxia on stem cell function, embryonic development, and tumor growth. Genes Dev 2006, 20:557-570
71. Martins Metelo A, Noonan HR, Li X, Jin Y, Baker R, Kamentsky L, Zhang Y, van Rooijen E, Shin J, Carpenter AE, Yeh JR, Peterson RT, Iliopoulos O: Pharmacological HIF2alpha inhibition improves VHL disease-associated phenotypes in zebrafish model. J Clin Invest 2015, 125:1987-1997

72. Levinson RS, Batourina E, Choi C, Vorontchikhina M, Kitajewski J, Mendelsohn CL: Foxd1-dependent signals control cellularity in the renal capsule, a structure required for normal renal development. Development 2005, 132:529-539

73. Nakagawa N, Xin C, Roach AM, Naiman N, Shankland SJ, Ligresti G, Ren S, Szak S, Gomez IG, Duffield JS: Dicer1 activity in the stromal compartment regulates nephron differentiation and vascular patterning during mammalian kidney organogenesis. Kidney Int 2015, 87:1125-1140

74. Majumdar A, Vainio S, Kispert A, McMahon J, McMahon AP: Wnt11 and Ret/Gdnf pathways cooperate in regulating ureteric branching during metanephric kidney development. Development 2003, 130:3175-3185

75. Narlis M, Grote D, Gaitan Y, Boualia SK, Bouchard M: Pax2 and pax8 regulate branching morphogenesis and nephron differentiation in the developing kidney. J Am Soc Nephrol 2007, 18:1121-1129

76. Park JS, Valerius MT, McMahon AP: Wnt/beta-catenin signaling regulates nephron induction during mouse kidney development. Development 2007, 134:2533-2539

77. Yi T, Tan K, Cho SG, Wang Y, Luo J, Zhang W, Li D, Liu M: Regulation of embryonic kidney branching morphogenesis and glomerular development by KISS1 receptor (Gpr54) through NFAT2and Sp1-mediated Bmp7 expression. J Biol Chem 2010, 285: $17811-17820$

78. Santos OFP, Barros EJG, Yang XM, Matsumoto K, Nakamura T, Park M, Nigam SK: Involvement of hepatocyte growth-factor in kidney development. Dev Biol 1994, 163:525-529

79. Woolf AS, Kolatsijoannou M, Hardman P, Andermarcher E, Moorby C, Fine LG, Jat PS, Noble MD, Gherardi E: Roles of hepatocyte growth factor/scatter factor and the met receptor in the early development of the metanephros. J Cell Biol 1995, 128:171-184

80. Costantini F, Kopan R: Patterning a complex organ: branching morphogenesis and nephron segmentation in kidney development. Dev Cell 2010, 18:698-712

81. Yanai K, Saito T, Kakinuma Y, Kon Y, Hirota K, TaniguchiYanai K, Nishijo N, Shigematsu Y, Horiguchi H, Kasuya Y, Sugiyama F, Yagami K, Murakami K, Fukamizu A: Renin-dependent cardiovascular functions and renin-independent blood-brain barrier functions revealed by renin-deficient mice. J Biol Chem 2000, 275: $5-8$

82. Plazanet C, Arrondel C, Chavant F, Gubler MC: Fetal reninangiotensin-system blockade syndrome: renal lesions. Pediatr Nephrol 2014, 29:1221-1230 